Portland State University

PDXScholar

\title{
A population study of three iris (iridaceae) species native to the Siskiyou Mountains in southwestern Oregon and adjacent California
}

Carol Anne Wilson

Portland State University

Follow this and additional works at: https://pdxscholar.library.pdx.edu/open_access_etds

Part of the Botany Commons, and the Population Biology Commons

Let us know how access to this document benefits you.

\section{Recommended Citation}

Wilson, Carol Anne, "A population study of three iris (iridaceae) species native to the Siskiyou Mountains in southwestern Oregon and adjacent California" (1983). Dissertations and Theses. Paper 3401.

https://doi.org/10.15760/etd.5286

This Thesis is brought to you for free and open access. It has been accepted for inclusion in Dissertations and Theses by an authorized administrator of PDXScholar. Please contact us if we can make this document more accessible: pdxscholar@pdx.edu. 
AN ABSTRACT OF THE THESIS OF Carol Anne Wilson for the Master of Science in Biology presented December 9, 1983.

Title: A Population Study of Three Iris (Iridaceae) Species Native to the Siskiyou Mountains in Southwestern Oregon and Adjacent California.

APPROVED BY MEMBERS OF THE THESIS COMMITTEE:

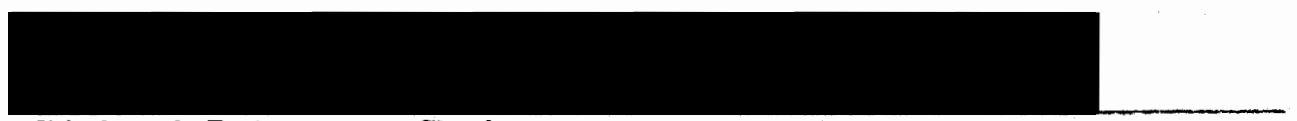

Richard Petersen, Chairman

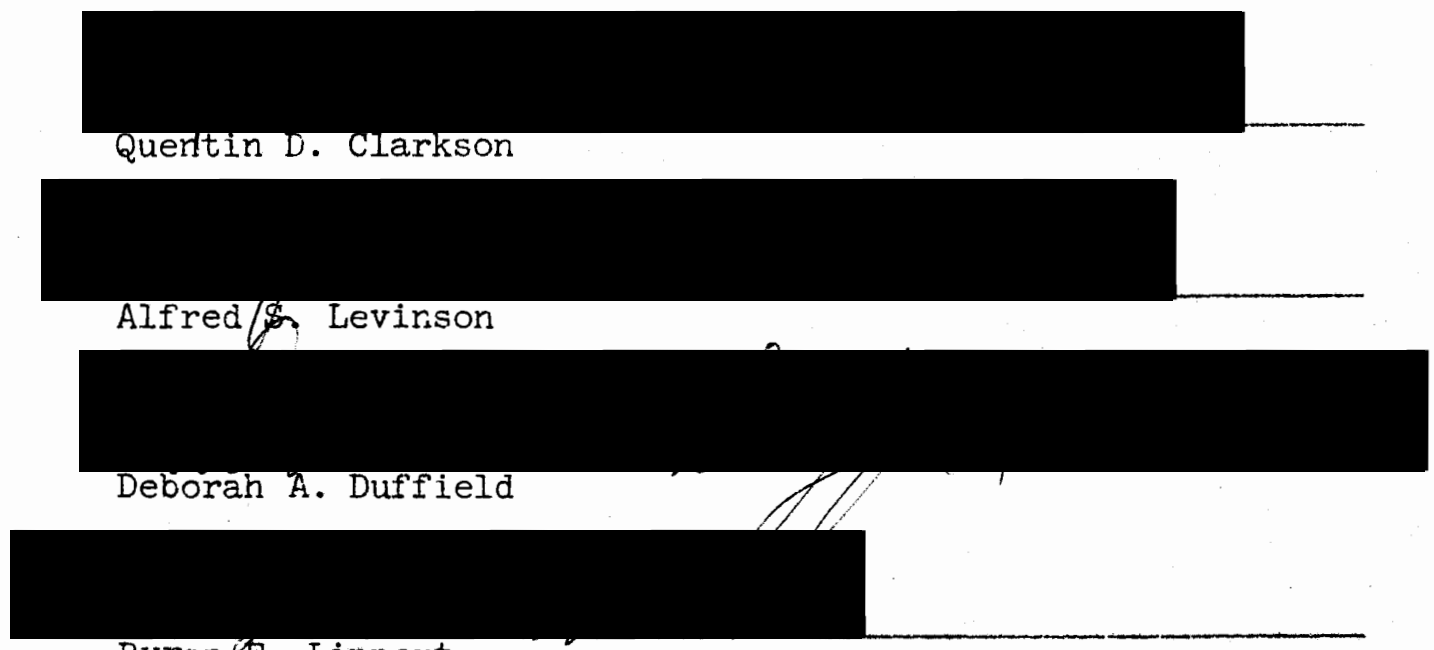

Byron 4 . Lippert

The series Californicae is a natural grouping of Iris species native to Oregon, Washington and California. Natural and experimental hybridization is characteristic of the series which has led to confusing taxononies for some species. Populations of species belonging to this series and found on the northwestern slopes of the Siskiyou Mountains of southwestern Oregon and adjacent California were investigated. Methods used 
were numerical classification techniques for morphological characters including both discriminant and $\mathrm{K}$-means cluster analyses and a chemotaxonomic analysis of flavonoid pigments using thin layer chromatography.

The thirteen populations were found to represent three species: Iris douglasiana, Iris innominata, and Iris thompsonii. This study does not support the current taxonomy for $I$. thompsonii which places it under $I$. innominata as a color form or in some populations as a hybrid between the species and I. douglasiana. Differences were found in the intraspecific variation of the three species. I. innominata was a homeogeneous species and $I$. thompsonii was quite variable over its range. These differences may well reflect the unique character of this area. Although hybridization is possibje between sympatric populations over the entire study area, mechanisms such as habitat preference and blooming time may well reduce gene flow. Two populations were found which may represent current hybridizations. 
A POPULATION STUDY OF IHREE IRIS (IRIDACEAE) SPECIES NATIVE TO THE SISKIYOU MOUNTAINS IN SOUTHWESTERN OREGON AND ADJACENT CALIFORNIA

by

Carol Anne Wilson

A thesis submitted in partial fulfillment of the requirements for the degree of

\author{
MASTER OF SCIENCE \\ in \\ BIOLOGY
}

Portland State University

1984 
TO THE OFFICE OF GRADUATE STUDIES AND RESEARCH

The members of the Committee approve the thesis of Carol Anne Wilson presented December 9, 1983 .

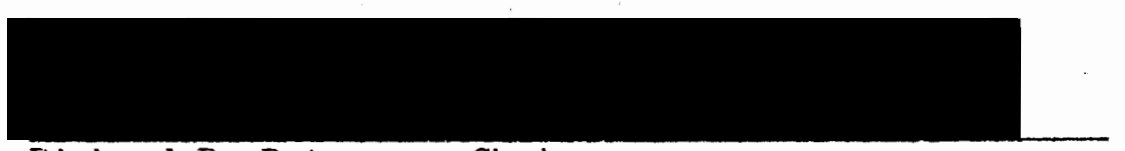

Richard R. Petersen, Chairman

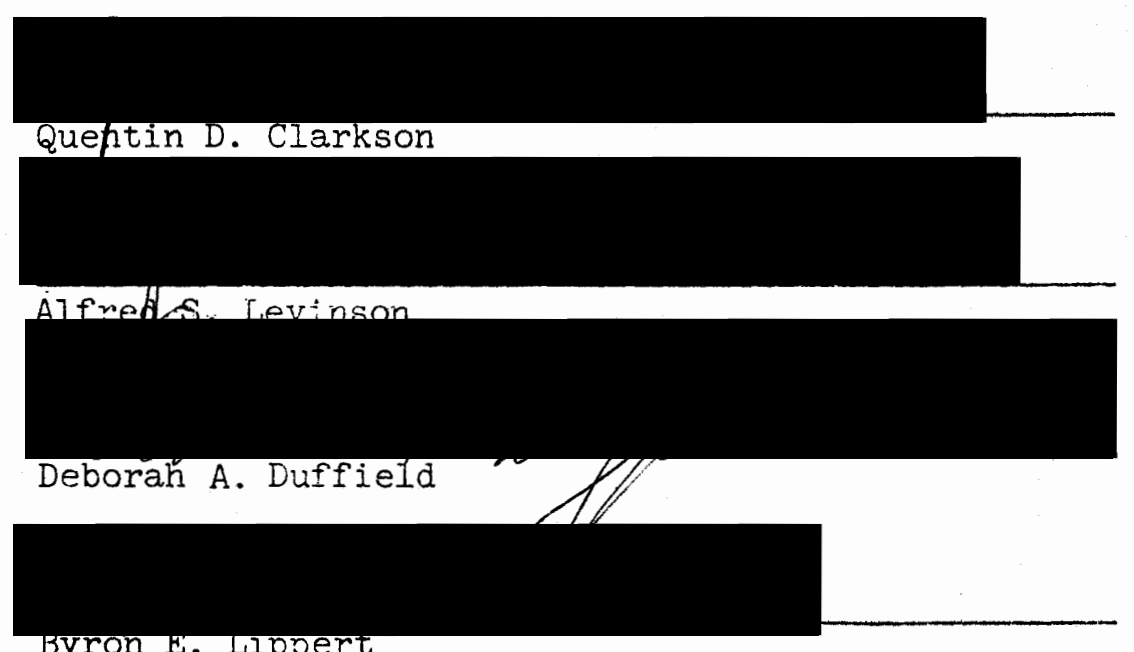

Byron \&. LIppert

APPROVED:

W. Herman Taylor, Head, Departuent of Biology

Stanley E. Rauch, Dean of Graduate Studies and Research 
TABLE OF CONTENTS

PAGE

LIST OF TABLES $\ldots \ldots \ldots \ldots \ldots \ldots \ldots \ldots \ldots \ldots \ldots \ldots \ldots \ldots \ldots \ldots$

LIST OF FIGURES $\ldots \ldots \ldots \ldots \ldots \ldots \ldots \ldots \ldots \ldots \ldots \ldots \ldots \ldots \ldots$

\section{CHAPTER}

I INTRODUCTION $\ldots \ldots \ldots \ldots \ldots \ldots \ldots \ldots \ldots \ldots \ldots \ldots \ldots \ldots \ldots$

II LITERATURE REVIEW $\ldots \ldots \ldots \ldots \ldots \ldots \ldots \ldots \ldots \ldots \ldots \ldots \ldots \ldots$

Taxonomy $\ldots \ldots \ldots \ldots \ldots \ldots \ldots \ldots \ldots \ldots \ldots \ldots \ldots \ldots \ldots$

Numerical Taxonomy $\ldots \ldots \ldots \ldots \ldots \ldots \ldots \ldots \ldots \ldots \ldots . \ldots . \ldots$

Flavonoids in Chemotaxonomy ................ 7

II RESEARCH PROBLEM $\ldots \ldots \ldots \ldots \ldots \ldots \ldots \ldots \ldots \ldots \ldots \ldots \ldots \ldots \ldots \ldots$

IV STUDY POPULATIONS $\ldots \ldots \ldots \ldots \ldots \ldots \ldots \ldots \ldots \ldots \ldots \ldots \ldots \ldots$

$\mathrm{V}$ MATERIALS AND METHODS ..................... 20

Numerical Analysis ...................... 20

Flavonoid Analysis ...................... 22

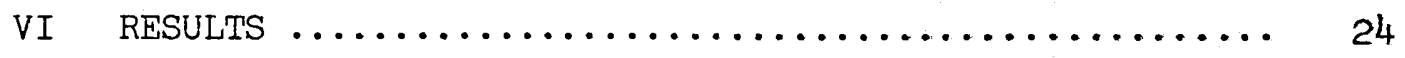

Numerical Analysis ..................... 24

Flavonoid Analysis ...................... 35

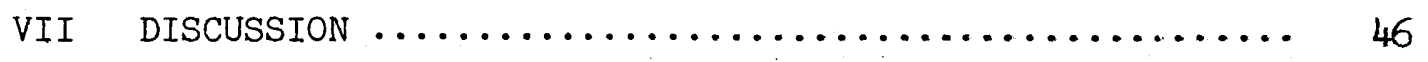

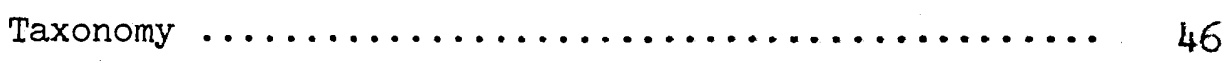

Origin of Iris thompsonii ............... 48

Intraspecific Variation $\ldots \ldots \ldots \ldots \ldots \ldots \ldots \ldots \ldots$ 
CHAPTER

PAGE

Current Hybridization 52

VIII CONCLUSIONS $\ldots \ldots \ldots \ldots \ldots \ldots \ldots \ldots \ldots \ldots \ldots \ldots \ldots \ldots \ldots \ldots$

LITERATURE CITED $\ldots \ldots \ldots \ldots \ldots \ldots \ldots \ldots \ldots \ldots \ldots \ldots \ldots \ldots \ldots \ldots \ldots \ldots$ 


\section{LIST OF TABLES}

TABLES

PAGE

I. Serpentine vs. Nonserpentine Soil for the Study Sites ...... 14

II. Blooming Times for the Study Sites ................ 15

III. Weight of Floral Parts and Volumn of Solvent Used ........ 22

IV. Classification of Populations Using Discriminant Analysis ... 24

V. Statistics for the Discriminant Analysis .............. 25

VI. Variables Included Stepwise in the Discriminant Analysis .... 26

VII. Group Statistics for the Thirteen Variables ............ 27

VIII. Group and Population Discriminant Scores .............. 28

IX. Classification of Populations Using Cluster Analysis ...... 31

$X$. A Comparison of the Average Mean Distance to the

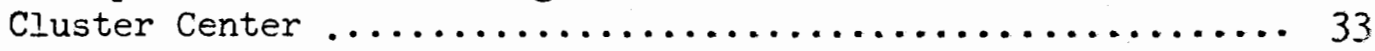

XI. Cluster and Population Mean Distances to Cluster Center ..... 34

XII. Summary of Flavonoid Spots Resolved from all Populations .... 36

XIII. Flavonoid $R_{f}$ Values for Populations of Group $1 \ldots \ldots \ldots . . . . .37$

XIV. Flavonoid $R_{f}$ Values for Populations of Group $2 \ldots \ldots \ldots$

XV. Flavonoid $R_{f}$ Values for Populations of Group $3 \ldots \ldots . \ldots 40$

XVI. Flavonoid $R_{f}$ Values for Champion Park .............. 43

XVII. Flavonoid $R_{f}$ Values for Iron Mountain II ............. 44 


\section{LIST OF FIGURES}

FIGURE

PAGE

1. Map of the Study Area with Study Populations Shown ........ 2

2. Graph of Discriminant Scores for the Three Groups ........ 29

3. Graph of Discriminant Scores for Group $1 \ldots \ldots \ldots \ldots \ldots \ldots$

4. Graph of Discriminant Scores for Group $2 \ldots \ldots \ldots \ldots \ldots \ldots$

5. Graph of Discriminant Scores for Group $3 \ldots \ldots \ldots \ldots \ldots$

6. Graph of Discriminant Scores for Champion $\mathrm{Pk}$. ......... 32

7. Graph of Discriminant Scores for Iron Mt. II .......... 32

8. Map of Flavonoid Spots, Group $1 \ldots \ldots \ldots \ldots \ldots \ldots \ldots \ldots$

9. Map of Flavonoid Spots, Group $2 \ldots \ldots \ldots \ldots \ldots \ldots \ldots \ldots$

10. Map of Flavonoid Spots, Group $3 \ldots \ldots \ldots \ldots \ldots \ldots \ldots \ldots$

11. Map of Flavonoid spots, Champion $\mathrm{Pk}$.............. 45

12. Map of Flavonoid Spots, Iron Mt. II $\ldots \ldots \ldots \ldots \ldots \ldots \ldots$

13. Map of Study Area Showing Species Distribution ............ 49 


\section{INTRODUCTION}

The series Californicae in the genus Iris (Iridaceae), contains eleven Pacific Coast species which are thought to be closely related. The series has been recognized as a unique and natural grouping of species since Dykes' (1913) comprehensive monograph on the genus Iris. Three species within this group: Iris douglasiana, Iris innominata and Iris thompsonii were investigated by Lenz (1958) in his revision of the Pacific Coast species and again in his papers on hybridization and speciation in the group (1959a). Clarkson (1958, 1962) also investigated the relationships between these three species. Much of his work centered on natural and experimental hybrids between I. douglasiana and I. innominata. Viable hybrid offspring are characteristic of the entire series. In nature $I$. douglasiana,. I. innominata and I. thompsonii have an overlapping distribution. Habitat requirements and blooming time might well reduce hybridization in natural populations.

I. douglasiana,. I. innominata and $I$. thompsonii are found in the Siskiyou Mountains which are part of the Klamath Mountain Range. The Klamath Mountain Range occupies a position south of the Coast Range and west of the Cascade Range in southwestern Oregon and extends into northwestern California north and west of the Sierra Nevada Range (Figure 1, inset). A major serpentine soil area occupies much of the Siskiyou Mountains. The parent rock material is primarily olivine, $(\mathrm{Mg}, \mathrm{Fe})_{2} \mathrm{SiO}_{4}$, but other minerials such as garnierite, $(\mathrm{Ni}, \mathrm{Mg}) \mathrm{SiO}_{3} \cdot \mathrm{nH}_{2} \mathrm{O}$, and chromite, $\mathrm{FeCr}_{2} \mathrm{O}_{4}$ are often present (White, 1971). These variations in rock material as well as differential weathering are seen in the variation of rock color from shiny 


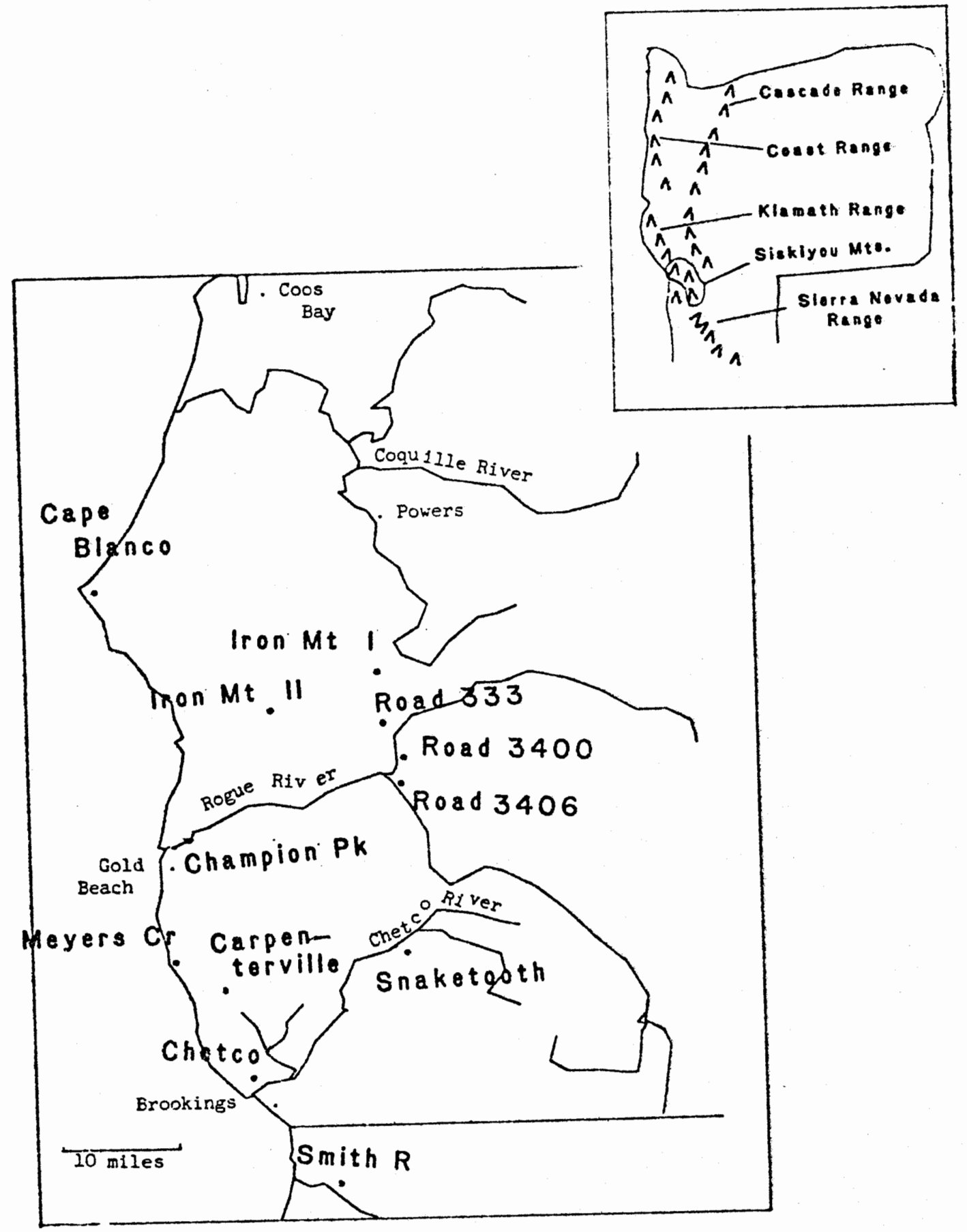

Figure 1. Map of the study area with otudy populations shown 
green to biuish and almost black in some cases. The resulting soils are usually reddish brown or gray in color. They form a thin mantle over the parent rock but on steep slopes erosion may prevent soil buildup and on level ground organic materials and clay may form a soil of considerable depth, especially on moist sites.

Serpentine areas are characterized by infertile, sparsely vegetated areas and a rich endemic flora. The endemic floras found in serpentine soils are thought to develop through a combination of heavy metal toxicity and low nutrient levels, particularly a lack of adequate levels of calcium (Walker, 1954 and Kruckeburg, 1954). These conditions cause both a sparse vegetation where few tree species can survive and the endemic fora of unusual serpentine tolerant taxa. Adaptation to serpentine soils is thought to be advaritageous to plants which do not compete successfully in the sur-rounding non-serpentine habitats. 


\section{LITERATURE REVIEW}

\section{Taxonomy}

In his monograph on the genus Iris, Dykes (1913) placed Iris dougZasiana Herb. within the subsection Californicae, a group of beardless, rhizomatous members of the Iridaceae which are found along the Pacific Coast in Washington, Oregon and California. Iris innominata Henders. and Iris thompsonii Foster when described were recognized as members of this group by their respective authors. Diels (1930) adopted this classification in his work on the genus. Foster (1937) also followed Dykes' classification of this group in his work on the genus. Previous to Dykes and subsequent workers the Pacific Coast iris were not separated from other beardless and rhizomatous species.

Lawrence (1953) did not propose changes for the three species of concern in his reclassification of the genus. He did however, propose changes in nomenclatural status. The genus Iris is large, with approximately 200 described species distributed in both the Old and New World of the Northern Hemisphere. Dykes, Diels and Foster classified these 200 species in two categories: section and subsection, subordinant to the genus. Iawrence found such a grouping to be unwieldy and at times incorrect. He recognized four infrageneric categories: subgenus, section, subsection and series. Under this classification the three Siskiyou species along with other Pacific Coast iris were placed in the subgenus Iris. The subgenus Iris contains all of the rhizomatous species. The Pacific Coast species were placed in the section Spathula in the subgenus Iris with all other species that are beardless. Spathula species are distributed among four 
subsections based upon branching pattern, lack or presence of a crest on the perianth parts and seed morphology. I. douglasiana,. I. innominata and $I$. thompsonii were placed in the subsection Apogon which includes all species lacking dichotomously branching stems, with perianth parts lacking a crest and with seeds lacking an aril, dispersing with capsule dehiscence and colored other than vermillion-red. Lawrence retained Dykes' Californicae species intact, however he reduced the group to a series within the subsection Apogon.

Clarkson (1958, 1959), in his work on the series Californicae proposed several changes in the series. Based upon cytological and morphological evidence $I$. tenuis was moved into a newly proposed subsection Oregonae consisting of a single species. He proposed further taxonomic changes within the series by reducing the six remaining species found in Oregon to the subspecific rank under I. tenax. This change was based upon the absence of cytological barriers and the presence of natural hybrids. He referred to the possible hybrid origin of $I$. thompsonii (I. tenax ssp. thompsonii) but retained it as a separate subspecies of equal rank to $I$. innominata (I. tenax ssp. innominata) and I. douglasiana (I. tenax ssp. douglasiana), the proposed parental stocks, because it formed distinct colonies at slightly different elevations than either proposed parent. Clarkson's taxonomic treatment of the six Oregon species within the series was not adopted by subsequent workers.

Five Oregon species were recognized by Lenz (1958, 1959 a) in his revision of the series Californicae and subsequent paper on hybridization and specation in the series. He recognized $I$. douglasiana and I. innominata but retained $I$. thompsonii within the species $I$. innominata, considering it a 
hybrid between the two species and in some populations as a color form of I. innominata. Lenz (1959b) transferred I. tenuis to the subsection Evansia, citing morphological data supporting its closer affinity to this group. Clarkson (1962) described further field studies of the species in which $I$. thompsonii was found to be intermediate in morphological and ecological characters between $I$. douglasiana and $I$. innominata. of particular importance to the study was the soil nitrogen and total base composition of the species' habitat. A low nitrogen to base ratio indicates the presence of serpentine soils. He concluded that I. douglasiana was found in open, grassy areas that were high in total nitrogen and low in total bases while I. innominata was found where soil nitrogen was low and total bases were high. I. thompsonii was found to occupy an intermediate habitat and thus to have utilized a niche not occupied by either parent.

\section{Numerical Taxonomy}

A taxonomy based upon morphological differences has been the basis for plant systematics since Linnaeus wrote Species Plantarum in 1753. Throughout botanical history there has been an attempt to further quantify morphological differences in explaining the classification of plant groups. In his thesis approximately 30 years ago Wagner developed the Groundplan Divergence Method of analysis, which has been the basis for many new concepts in cladistics (Wagner, 1980). His method is composed of three basic steps. First a systematic analysis is proposed based upon measures of similarities and differences, a common ancestor is then proposed and finally, divergences are calculated and a phylogeny is developed based upon shared divergences and the number of divergences.

The Groundplan Divergence Method as proposed by Wagner uses heir- 
archical methods. Such methods are often not as useful at the species level and lower as differences between taxa may not be as pronounced and may not lead to a phylogeny (Jordene and Edmonds, 1974). Non-heirarchical methods such as discriminant analysis, cluster analysis, and character compatibility have been developed to analyse such data sets. Duncan (1980) proposed that cladistic analysis could be used for character states leading to a character state tree similar to heirarchical methods but based on the evolution of characters. He used character divergences similar to Wagner's method of species divergences in a cluster analysis of Ranunculus hispidis. Non-heirarchical and heirarchical methods can be expanded to include all the known genetic characters. Elington (1978) used cytological and chemical data as well as morphological data in his study of AlZium species within the subgenus Molium.

Flavonoids in Chemotaxonomy

Flavonoids, water soluble pigments found usually in the cell vacuole, are considered by many botanists to be the most useful metabolic end products for taxonomic studies. Harborne (1975) points out such features as their widespread distribution, stability, ease of detection and immense structural variability with more than 1,000 flavonoids described. The roles of these common compounds are not entirely known. Flavonoid contribution to floral color is thought to be important in pollinator attraction. Other roles of importance to the plant are thought to be as fungical and antibiotic agents and as light screens. (Swaim, 1973).

Mendel reported the genetic basis for flower color in 1865 from his work with garden peas. After rediscovery of his work in 1900 the inheritance of flower color was further investigated by geneticists. OnsIow in 
1930, investigated the chemical events controlled by genetics. She proposed while working with Antirrhinum that a chemical such as a pigment could be correlated with a single gene chenge (Clevenger, 1964). Hannan (1981) investigated flower color polymorphism in Platystemon californicus and found the following evidence for genetic control: 1 . All flowers on a plant regardless of age, had the same color pattern and the petal color of individual flowers was constant over the life of the flower. 2. The same color polymorphisms found in natural populations occurred also in cultivated progeny of plants from the population, inaicating that environmental factors did not control flower color. 3. Progeny of intermorph crosses showed segregation of only the morphs fourd in the atural parent population.

Flavonoid compounds are classified according to the level of oxida.tion of the heterocyclic chain. The three most common groups are represented by the following basic structures. Further modifications include

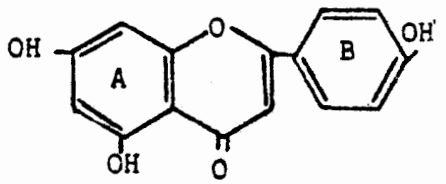

Flavones

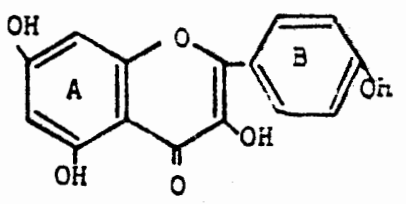

Flavonols

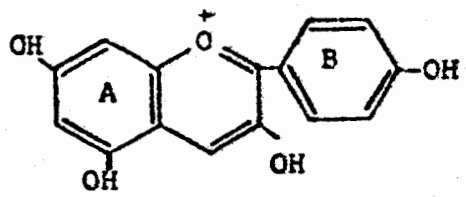

Anthocyanidins

methylation of the flavonoid nucleus or hydroxyl groups, methylenation of ortho-dihydroxyl groups, glycosylation of hydroxyl groups to produce 0-gly cosides and the addition or removal of hydroxyl groups. The pigments are almost always present as glycosides where commonly one or two glucose units are present on the hydroxyl group of the heterocyclic ring or on the 5 
carbon of the A-ring. Parks (1965) found glycosides commonly at the $\mathrm{C}_{7}$ and $\mathrm{C}_{3}$ position in Gossypium and felt that sugar units could occur on the B-ring also.

Each substituent added onto the flavonoid nucleus occurs in discrete steps generally thought to be under the control of a single gene. Substituent variants are therefore seen as gene markers at the species level. Many studies have used chemical analysis of flavonoids to resolve confusing taxonomic relationships. Umber (1980) used flavone chemistry to analyze eight sympatric taxa of Glandularia from the southwestern United States and Mexico. The taxa were thought to have widespread hybridization. He was able to distinguish four taxa from the complex, one of which consisted of two chemical races which were chromosomally and morphologically nondistinguishable but shared only five of fifteen total flavonoids resolved. Analysis of flavonoid chemistry does not always successfully establish relationships among taxa. Six closely related taxa of opuntia were investigated for flavonoid content by Clark and Parfitt (1980). Using liquid column chromotography they were unable to determine differences in the flavonoids produced. If differences were present in the flavonoid patterns investigated by Clark and Parfitt they may not have been detected due to similar flow values. Parks (1967) found that by using expanded techniques he was able to distinguish between flavonoid profiles that previously had been considered similar. Previous attempts by the author to distinguish differences between two species of Gossypium using two dimensional paper chromatography of plant flavonoids were not sufficient to discriminate between the two species. By using a preliminary separation in a column followed by two dimensional paper chromatography he 
was able to identify a total of twenty flavonoids of which only ten were common to both species. Park concluded that differences found using simple chromatography techniques demonst,rate real chemical differences but that similar chemical profiles may not indicate that taxa are the same chemically. He recommends further analysis for taxa that may have similar flavonoid compounds but are thought to have real differences. Hybrid species have also been analyzed with flavonoid chemistry. Most of this work has used polyploid hybrids where the expected results were an increased number of pigments as the hybrid would have the capacity to produce flavonoids of both parent taxa. Diploid hybrids are more difficult to detect and the prediction of genetic products is more obscure. Levy and Levin (1975) investigated the hybrid allotetraploid Phlox floridana and supposed diploid parent species $P$. carolina and $P$. pilosa ssp. dentosa. P. floridana produced ten glycoflavones common to $P$. carolina of which five were characteristic of the species and seven glycoflavones common to $P$. pilosa ssp dentosa of which three were characteristic for the species. P. floridana also synthesized two new flavones. The authors felt that increased complexity of biosynthetic pathways resulted in each of the new syntheses. In another study, Clark and Parfitt (1980) analyzed Opuntia species and their diploid and tetraploid hybrids for relative percentages of flavonol pigments. Tetraploid hybrids were found to have quantities of pigments intermediate between the two dipioid parents as predicted, however the diploid hybrids displayed unusual patterns where some levels of flavonols decreased while some increased over parental levels. 


\section{RESEARCH PROBLEM}

The relationships of three Siskiyou Mountain Iris species were investigated using population studies in their possible area of sympatry. Since it had been demonstrated previously that hybridization in this series leads to viable offspring and such offspring had been observed in nature for these species, one would expect to find considerable genetic exchange and the resultant "hybrid swarm" found among many plants such as opuntia species in Arizona (Clark et. al, 1980). By selecting populations distributed throughout the overlapping ranges of the species any interspecific variation found would be more meaningful. Specific questions of interest were: 1. How many species are represented by the study populations? 2. What evidence is there for the origin of Iris thompsonii? 3. What differences in intraspecific variation exits between the species? 4 . Is there evidence for current hybridization among the species?

Two methods of investigation were chosen. The first, a numerical analysis of morphological data using two computer programs suitable for taxonomic work, made possible the use of a large quantity of morphological data representing the thirteen study populations. In order to maximize the genetic basis for morphological differences, floral characters were preferred over vegetative characters. Floral parts are generally considered evolutionarily conservative and not subject to phenotypic plasticity, which is sometimes found associated with diverse habitats such as those found in the study area. Secondly, a chemotaxonomic analysis of floral flavonoids provided an independant measure of genetic similarities and differences between the populations. With this technique the color varia- 
tion in floral parts which had received unequal treatment by previous workers could be addressed more directly. 


\section{STUDY POPULATIONS}

Thirteen populations were chosen as study sites (Figure 1). All but one of these, the Smith River population in adjacent Del Norte County, California, are located in extreme southwestern Oregon. The populations represent the range in which the three species could be found sympatrically. Iris douglasiana is found as far south as Santa Barbara County, California but the other two species are restricted roughly to the area surveyed. Iris innominata has been collected about twenty kilometers east of Agness but Iris thompsonii is known only from the study area.

During the study, habitat preferences and differential blooming times were recognized as potential isolating mechanisms. These characteristics were recorded for each study site. As serpentine soil is the most obvious habitat characteristic in the study area, habitat preference was determined by the presence or absence of serpentine soil. Evidence used for determining soil characteristics were Clarkson's (1962) analysis of soil nitrogen and base ratios, Baldwin's (1981) treatment of the distribution of serpertine soils in the Klamath Mountain Range, Walker's (1954) description of floristic characteristics of serpentine versus nonserpentine areas and observations by the author of parent rock material. The soil characteristics are summerized in Table I and the evidence used is discussed under each study site description.

Blooming times were determined for the 1982 and 1983 field season by monthly visits from March through July to the study site. Peak bloom times were interpreted as that time when a majority of plants were fully in flower and during the flowering of the first or second bud in those 
TABLE I

SERPENTINE VS NONSERPENTINE SOIL FOR THE STUDY SITES

\begin{tabular}{ll}
\hline Study Site & Soil Characteristics \\
\hline Cape Blanco & nonserpentine \\
Meyers Creek & serpentine \\
Smith River & intermediate \\
Daphne Grove & serpentine \\
Iron Mountain I & serpentine \\
Carpenterville & serpentine \\
Chetco River & intermediate \\
Road 333 & intermediate \\
Road 3400 & nonserpentine \\
Road 3406 & intermediate \\
Snaketooth & nonserpentine \\
Champion Park & nonserpentine \\
Iron Mountain II & serpentine \\
\hline
\end{tabular}

populations where more than one flower is found per inflorescence. Blooming times are summarized for each population in Table II. The study sites are roughly arranged in the table from the northern edge of the study site to the southern edge to emphasize the proximity of populations to each other.

Cape Blanco State Park

Large leaved, purple plants were plentiful in this area. The popu- 
lation studied is located near the radio tower 2.3 miles from $\mathrm{Hwy} 10 \mathrm{l}$ on the road leading to Cape Blanco. The plants were found growing in large, healthy clumps in a small grove of Douglas fir and in the surrounding

\section{TABLE II}

BLOOMING TIMES FOR THE STUDY SITES

\begin{tabular}{|c|c|c|c|c|c|}
\hline Study Site & March & April & May & June & July \\
\hline Cape Blanco & no & no & no & peak & yes \\
\hline Daphne Grove & no & no & peak & yes & no \\
\hline Iron Mountain I & no & no & peak & yes & no \\
\hline Iron Mountain II & no & no & $?$ & yes & no \\
\hline Road 333 & no & no & peak & yes & no \\
\hline Road 3400 & no & no & yes & no & no \\
\hline Road 3406 & yes & peak & yes & no & no \\
\hline Champion Park & no & no & peak & yes & $?$ \\
\hline Meyers Creek & yes & peak & yes & yes & no \\
\hline Carpenterville & no & no & no & yes & yes \\
\hline Chetco River & yes & peak & yes & no & no \\
\hline Snaketooth & no & no & peak & yes & no \\
\hline Smith River & no & no & no & yes & yes \\
\hline
\end{tabular}

open, grassy area. This area would be expected to have a nonserpentine soil based upon the occurrence of Douglas fir and numerous grasses. Its location also indicates a nonserpentine habitat as serpentine is thought to not occur near the ocean in this location along the coast. Associated species are Pseudotsuga menziesii, Polystichum munitum, and Poaceae species. 
Carpenterville

Small leaved, purple iris were found growing on the roadbank 5.1 miles past the Cape Ferrel Road intersection on Carpenterville Road. This area was found by Clarkson to be high in total bases and Iow in nitrogen, indicating a serpentine habitat. Associated species were mosses, Sedum species and ferns.

Champion Park

In this newly logged area near Champion Park, 6.4 miles northwest of Hwy 101 along the Rogue River, large leaved plants with floral color variation from yellow to purple were growing. The habitat was open and hilly. The soil would not be expected to be serpentine as the vegetation was typical of a nonserpentine habitat and serpentine is not thought to be located as close to the ocean as this site is in this area. Associated species were Poaceae species and Equisetum species, however Douglas fir had been replanted.

\section{Chetco River}

Small clumps of small leaved, purple iris were scattered along the roadbank two miles east of the junction of Hwy $10 \mathrm{l}$ and the North Bank Chetco River Road. Plants were restricted to open areas near the base of the roadbank. Clarkson found this area to be intermediate in measured total bases and total nitrogen. Associated species were quercus chrysolepis, Xerophyllum tenax and Gaul theria ovatofolia.

\section{Daphne Grove}

Scattered along the roadbank from 2.4 miles east of Daphne Grove on 
Road 333 were. small leaved, yellow iris. Clarkson found a Iow nitrogen to base ratio typical of serpentine soils at this site. Greenish rocks could be seen on either side of the Coquille River further supporting the presence of serpentine. The plants were found in small numbers growing under laurel trees and amongst the roadside grasses. Associated species were Umbelularia california, Arctostaphyllus species and Poaceae species.

Iron Mountain I

This area aptly fits the habitat description for Iris innominata. The soil is gravelly with sparse vegetation consisting of Xerophylzum tenax, Arctostaphylus species and Rhododendron macrophyllum. Small Ieaved, yellow plants made up the iris population here. The population is located where Iron Mountain Road leaves Road 333. The soil would be expected to be serpentine both because of the associated species which are typical of serpentine habitats and also because of the known distribution of serpentine soils which are especially prevalent on Iron Mountain.

Iron Mountain II

A population of purple, cream, yellow and white plants was found ten miles from the intersection of Iron Mountain Road with Road 333 on Iron Mountain Road. The soil is known to be serpentine in this area, however grasses and Douglas fir were more common at this site in comparison to the first Iron Mountain site. Associated species were Psuedotsuga menziesii, Arctostaphylus species and Poaceae species.

\section{Meyers Creek}

This population of plants is located along Hwy 101 where a large serpentine outcrop was seen. The site is located about 100 yards north 
of Meyers Creek where it crosses Hwy 101. The soil is presumed to be of serpentine origin due to the large outcrop. Plants were callected from damp seepages and drier hillsides. The study site was grazed by sheep and contained primarily Poaceae species.

$\underline{\text { Road } 333}$

A multicolored population was found 3.9 miles north of the junction of Ilahe Road and Road 333 on Road 333. Iris were found along the roadside and on steep ground both above and below the road. The soil was considered intermediate based upon the presence of both serpentine and nonserpentine taxa. Associated species were Pseudotsuga menziesii, Quercus chysolepis and Poaceae species.

$\underline{\text { Road } 3400}$

A small leaved iris population was found 150 yards east of Road 333 on Road 3400. The purple plants were found occurring singly on small knolls above the road. A few yellow plants were seen in small clumps along the road. The area is hilly with open grassy areas. Based upon the grassy habitat and other associated species the soil was determined to be nonserpentine. Associated species were Pseudotsuga menziesii, Dodecatheon species, Allium watsonii and Poaceae species.

$\underline{\text { Road } 3406}$

In high humus soil and partial shade, small leaved, purple iris were growing under Douglas fir. Here, 0.8 miles up Road 3406 from Road 333 , the plants were plentiful but scattered in the grassy understory. The soil was determined to be intermediate based upon the vegetation which is typical for an intermediate habitat. Associated species were Pseudotsuga 
menziesii, Dodecatheon species, Quercus chysolepis, Cirsium pastoris, and Poaceae species.

\section{Snaketooth}

Small leaved, purple plants were collected 9 miles past the Snaketooth Road turnoff on the North Bank Chetco River Road. In 198 I the plants were growing in light shade under Douglas fir and in open, grassy areas. The population had been bulldozed when it was visited in 1982. Individuals were still found although they were restricted to the roadside and were not plentiful. Associated species were Pseudotsuga menziesii and Poaceae species indicating a nonserpentine soil.

Smith River

At this study site in California large leaved, purple plants were growing. The site is 6 miles east on Hwy 97 from Hwy 10I, near Jedediah Smith State Park. Clarkson measured soil bases and nitrogen here and found the soil to be intermediate between that expected for serpentine or nonserpentine. Associated species were Sequoia sempervirens, Lilium pardalinum and Poaceae species. 


\section{MATERIALS AND METHODS}

Numerical Analysis

Floral and vegetative parts were collected during the spring and early summer of 1982 and 1983. They were measured in the field while still fresh. Populations were collected as near as possible to peak blooming time. Peak blooming time was interpreted as that time when a majority of plants were fully in flower and during the flowering of the first or second bud in those populations where more than one flower is found per inflorescence. Measurements taken were: \# of cauline leaves, \# of flowers per inflorescence, bract length, bract width, petal. length, petal width, sepal length, sepal width, stigma length, stigma width, peduncle length, and floral tube length. In all cases lengths of parts were determined by measuring from the base of the part to the tip and width was determined by measuring the widest point. The stigma was widest at the highest point of the crest and that measurement was used. Bract measurements used in the analysis were from the bract subtending the flower in bloom. Measurements of the peduncle were taken from the ovary base to the junction of the peduncle with the stem. Floral tube length was determined from the point of divergence of the sepals to the base of the floral tube. A qualitative evaluation of flower color was also recorded.

Data sets were stored on a Honeywell computer for access by the two programs used. Discriminant analysis was generated by use of the SPSS DISCRIM (1982) program (Nie et al., 1975). Fifteen variables were used including two dummy variables indicating whether the flower color was 
purple, yellow, or neither purple or yellow. A stepwise procedure which identifies the variables in order of importance was used. Importance was determined by the Wilks' Method of Inclusion. This technique considers both the homogeneity of the groups and the distance between centroids. The variable is chosen for inclusion that maximizes the $F$ ratio and minimizes the Wilks' Lambda. Options used were a missing value card which excluded cases with missing values from the analysis but included them in the classification step and a card that computed all the available statistics.

A three group analysis representing the three species was performed. Individuals from populations recognized as being typical for each of the species were used to set up the classification. A total of 86 cases were used in computing the two discriminant functions. Cape Blanco was used to discriminate Group I, individuals from Daphne Grove and Iron Mountain I represented Group 2, and Group 3 was discriminated using Chetco River and Snaketooth populations. In the classification step 123 cases were unknowns.

Cluster analysis was then employed to the same data set. A K-Means program (Hartigan, 1975) modified for easier input and more case capacity by E. D. Shell at Portland State University was used. In this analysis those cases with missing data were excluded. The program executed ten internal iterations and computed a maximum of ten clusters using zero as a starting point. Thirteen variables were used in the analysis. Stem length was excluded due to both its variable nature and greater scale in rolation to the other variabjes used. Flower color was entered as ordinal data from 1 to 5, corresponding to flower colors white, yellow, blue, lavender, and purple respectively. 
Flavonoid Analysis

Floral parts were collected from ten populations during the 1982 and 1983 field seasons for flavonoid analysis. Floral parts were not collected from the Carpenterville, Smith River, and Road 3400 populations as these populations were very small. Neither Carpenterville nor Smith River are in areas of possible hybridization and Road 3400 is within two miles of Road 3406 which was analysed for flavonoid pigments. The collected floral parts were dried either in a plant press or spread on blotter paper and air dried on a lab bench. The parts from each population were then crumbled, weighed, placed in small flasks with acidified (10\% HCI) methanol (Table III) and left in the refrigerator for at least three days following the method developed by Park (1965).

TABLE III

WEIGHT OF FLORAL PARTS AND VOLUMN OF SOLVENT USED

Population

Cape Blanco

Champion Pk.

Chetco River

Daphne Grove

Iron Mt. I

Iron Mt II

Meyers $\mathrm{Cr}$.

Road 333

Road 3406

Snaketooth
Wt. in Grams

0.10

1.5

0.11

1.6

0.10

1.5

0.10

1.7

0.08

1.2

0.10

1.5

0.10

1.5

0.10

1.5

0.10

1.5

0.10

1.5 
A total of $20 \mu \mathrm{m}$ of extract was applied to each plate by repeated applications from a $5 \mu$ capillary pipet. The plates used were Analtech Avicel F $20 \times 20 \mathrm{~cm}$. microcrystaline cellulose thin layer glass plates. The plates were dried overnight before being developed.

Five standard thin layer tanks each holding two plates were used for simultaneous development of the ten extracts. For the first run, $100 \mathrm{ml}$ of TBA, tert-butanol: HOAc: $\mathrm{H}_{2} \mathrm{O}$ in the proportions $6: 2: 1$, was added to each tank (Markham, 1982). The atmosphere was saturated before adding the plates. Due to the long development time ( 7 hours) $\frac{1}{2}$ inch foam sheets were placed around the tanks as insulation. After removing the plates and drying them overnight, the solvent front was removed by scraping off the top $3: \mathrm{cm}$ of cellulose.

The tanks were then prepared for development in the second direction using the same procedure except that the solvent was modified from the standard TBA used previously. Tert-butanol: HOAc: $\mathrm{H}_{2} \mathrm{O}$ were used but in the proportions $3: 1: 1$. The plates were removed after 8 hours and dried. under a fume hood overnight. The dried plates were then observed under long and short wave UV light with a UVSL-25 mineralight and marked for pigment spots. 


\section{RESULTS}

Numerical Analysis

The Discriminant Analysis program generated two functions based on Mahalanobis distances for the variables used. The individual cases in the thirteen populations were then classified into one of three groups by the discriminant function. The populations classified to the three groups are shown in Table IV. Individuals from Champion Park and Iron Mountain II populations were not consistantly classified into any ore of the three groups.

\section{TABLE IV}

CLASSIFICATION OF POPULATIONS USING DISCRIMINANT ANALYSIS

\begin{tabular}{cccc}
\hline Group 1 & Group 2 & Group 3 \\
\hline Cape Blanco & Daphne Grove & Carpenterville & Road 3400 \\
Meyers Cr. & Iron Mt. I & Chetco River & Road 3406 \\
Smith River & & Snaketooth & Road 333 \\
\hline
\end{tabular}

The classification of the thirteen populations into three groups was found to be highly significant as shown in Table V. The Eigenvalues indicate that both functions are important in discriminating the populations studied. The first function which separated Group 1 from the other two groups was relatively more important as shown by the percent of total Eigenvalue for that function. The functions computed were found to be closely correlated to the groups discriminated as shown by the large values of the Cannonical Correlations. Furthermore, the discriminating power 
of the functions is large as indicated by the low Wilks' Lambda which corresponds inversely to a high Chi Square ( 467.48 and 172.02 respectively).

\section{TABLE V}

STATISTICS FOR THE DISCRIMINANT ANALYSIS

\begin{tabular}{ccccc}
\hline Function & Eigenvalue & $\begin{array}{c}\% \\
\text { of Total }\end{array}$ & $\begin{array}{l}\text { Cannonical } \\
\text { Correlation }\end{array}$ & Wilks' Lambda \\
\hline 1 & 44.25758 & 84.4 & 0.988804 & 0.0024006 \\
2 & 8.20420 & 15.6 & 0.9441154 & 0.1086461 \\
\hline
\end{tabular}

Three variables were excluded by the program as they did not contribute a significant degree of separation for the groups. The twelve variables included are listed in Table VI with their Wilks' Lambda and Equivalent $F$ scores. The mean values for the morphological variables are shown in Table VII. Group 3 was intermediate between Group 1 and Group 2 for mean character values except for three characters. These characters were number of cauline leaves, sepal width and floral tube length. Group 3 values were less than the other two groups for the first two characters but floral tube length exceeded the values found for Group I and Group 2 .

Table VIII gives the mean Discriminant scores resulting from the two functions for the three groups, each population assigned to one of the three groups and the two groups not consistently classified to any one of the three groups. The Discriminant Scores for the three groups are graphed in Figure 2. The Discriminant Scores for each individual within Group 1, Group 2 and Group 3 are graphed in Figures 3,4 and 5 respectively. The $X$ and $Y$ axes are all 12 units in length to emphasize the relative variability of Discriminant Scores for each group. 
TABLE VI

VARIABLES INCLUDED STEPWISE IN THE DISCRIMINANT ANALYSIS

\begin{tabular}{clcc}
\hline STEP & VARIABLE & WILKS' LAMBDA & EQUIVALENT F \\
\hline 1 & yellow petal color & 0.0454545 & 871.5000 \\
2 & number of flowers & 0.0113110 & 344.5075 \\
3 & bract length & 0.0069226 & 297.5119 \\
4 & purple petal color & 0.0050500 & 261.4380 \\
5 & floral tube length & 0.0041585 & 229.2134 \\
6 & petal length & 0.0035983 & 203.7174 \\
7 & bract width & 0.0033052 & 180.3358 \\
8 & stem length & 0.0029496 & 165.4199 \\
9 & petal width & 0.0027366 & 150.9659 \\
10 & \# cauline leaves & 0.0025084 & 137.0763 \\
11 & peduncle length & 0.0025084 & 125.8685 \\
\hline
\end{tabular}

Group I Discriminant Scores range from 6.5281 to 12.5411 for Function $I$ and -0.0808 to 7.7753 for Function II. Meyers Creek has scores which are more variable than other populations in this group. The individual occupying the lowest left position in Figure 3 was classified to Group 3 while other members of Meyers Creek were assigned to Group 1 . Group 2 scores were the least variable of the three groups as shown in Figure 4. Function I scores ranged from -5.8941 to -7.3728 and Function II scores ranged from -0.4479 to 2.0898. Group 3 discriminant Scores were the most variable. Scores for Function I were similar in spread to Group 1 with scores from 0.9450 to 7.0751 but Function II scores had a 
TABIE' VII

GROUP STATISTICS FOR THE THIRTEEN VARIABLES

\begin{tabular}{lcccccc}
\hline & \multicolumn{2}{c}{ Group I } & \multicolumn{2}{c}{ Group 2} & \multicolumn{2}{c}{ Group 3} \\
Variable & $\overline{\mathrm{x}}$ & $\mathrm{Sd}$ & $\overline{\mathrm{x}}$ & $\mathrm{Sd}$ & $\overline{\mathrm{x}}$ & $\mathrm{Sd}$ \\
\hline yellow petals & 0 & 0 & 0.98 & 0.15 & 0 & 0 \\
\# flowers & 3.06 & 0.44 & 1.00 & 0 & 1.41 & 0.50 \\
bract lngth & 7.37 & 0.78 & 4.17 & 0.62 & 4.53 & 1.19 \\
purple petals & 0.88 & 0.34 & 0 & 0 & 0.96 & 0.19 \\
fl tube lngth & 1.66 & 0.19 & 2.09 & 0.33 & 2.44 & 0.65 \\
petal lngth & 5.83 & 0.64 & 4.30 & 0.40 & 4.46 & 0.52 \\
bract wdth & 1.76 & 0.26 & 1.12 & 0.15 & 1.13 & 0.28 \\
stem lngth & 15.4 & 5.98 & 12.2 & 4.93 & 15.1 & 5.52 \\
petal wdth & 1.28 & 0.20 & 1.00 & 0.14 & 1.10 & 0.36 \\
\# caul lvs & 1.81 & 0.54 & 2.05 & 0.62 & 1.70 & 0.78 \\
pedun lngth & 2.50 & 0.94 & 0.85 & 0.62 & 0.90 & 0.44 \\
sepal wdth & 2.46 & 0.28 & 1.94 & 0.30 & 1.78 & 0.28 \\
\hline
\end{tabular}

greater spread than Group 1 scores. They ranged from -10.4816 to -1.0675 (Figure 5). The scores for Snaketooth range from 0.9450 to 6.1297 and from 0.2723 to -5.7686 for Functions I and II respectively. Considerable variation in Discriminant Scores is found in this population.

Two populations, Champion Park and Iron Mountain II, were not consistently classified to any one group. Thirteen cases from Champion Park were assigned to Group 1, two to Group 2 and two were assigned to Group 3. Even more striking than the classification of members of this population to each of the three groups were the Discriminant Scores for individuals 
TABLE VIII

GROUP AND POPULATION DISCRIMINANT SCORES

Group/Population

1

Cape Blanco

Smith River

Meyers Creek
Function I

$9 \cdot 3474$

9.3474

11.3297

9.9656

$-6.3251$

0.7083

Daphne Grove

$-6.2911$

0.6582

Iron Mountain I

$-6.5388$

0.8495
Function II

4.2927

4.2347

5.6285

4.8538
3

Chetco River

Road 333

Road 3400

Road 3406

Carpenterville

Snaketooth
4.5342

4.5326

4.2337

4.4228

4.0519

3.5286

4.2518
$-3.6730$

$-3.6729$

$-3.8594$

$-6.0955$

$-3.3652$

$-5.4735$

$-4.5402$
Champion Park

Iron Mountain II
7.2048

4.5906

0.2021
$-1.6734$ 


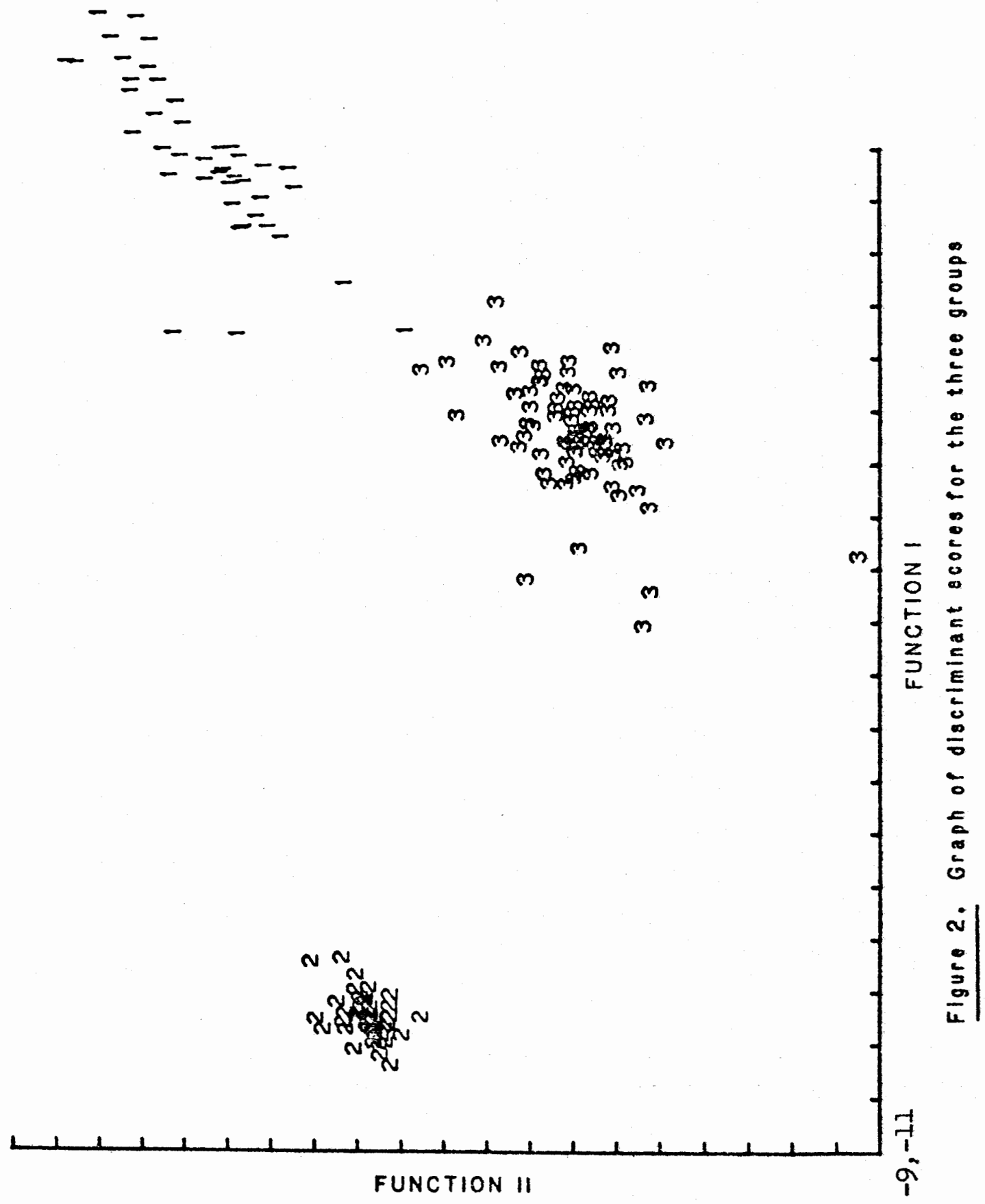




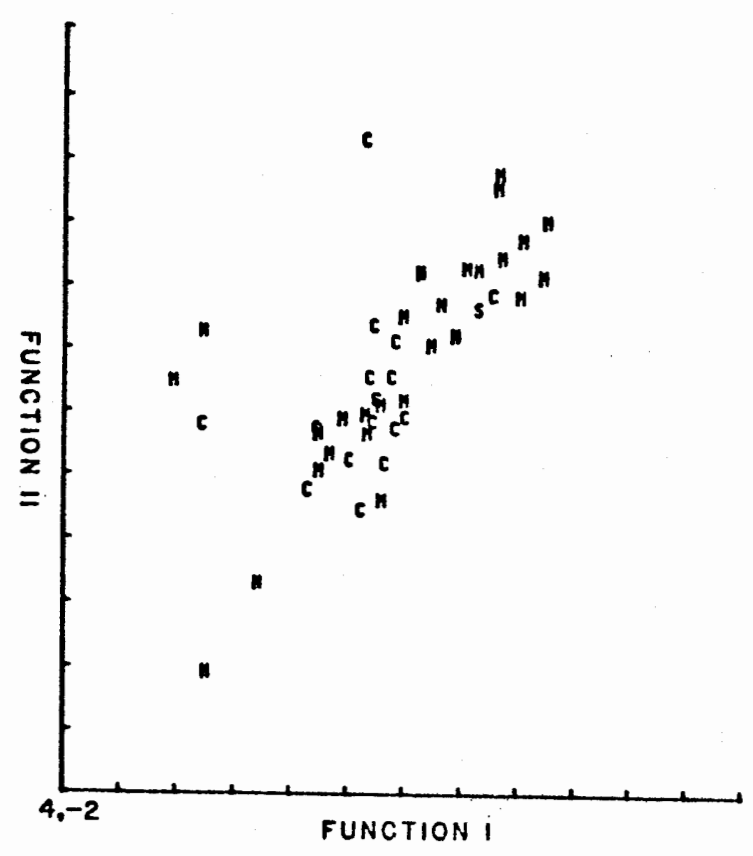

Figure 3. Graph of discriminant ocores for Group C-Capo Blanco S-Smith R. M-Moyors Cr.

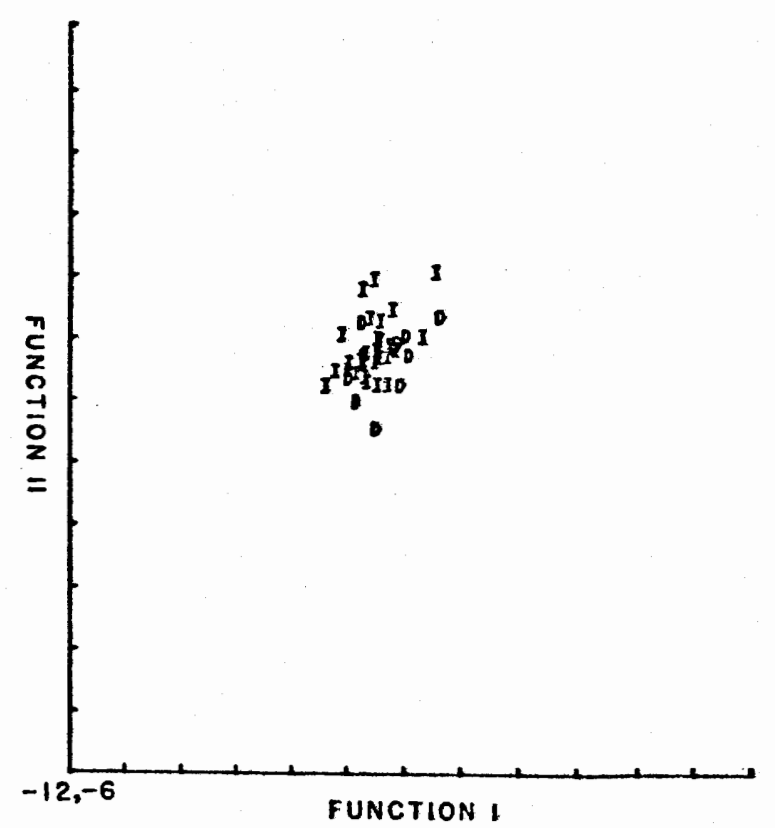

Figure 4. Graph of discriminant ecores fer Group 2 Tron Mt. D-Daphne Grove.

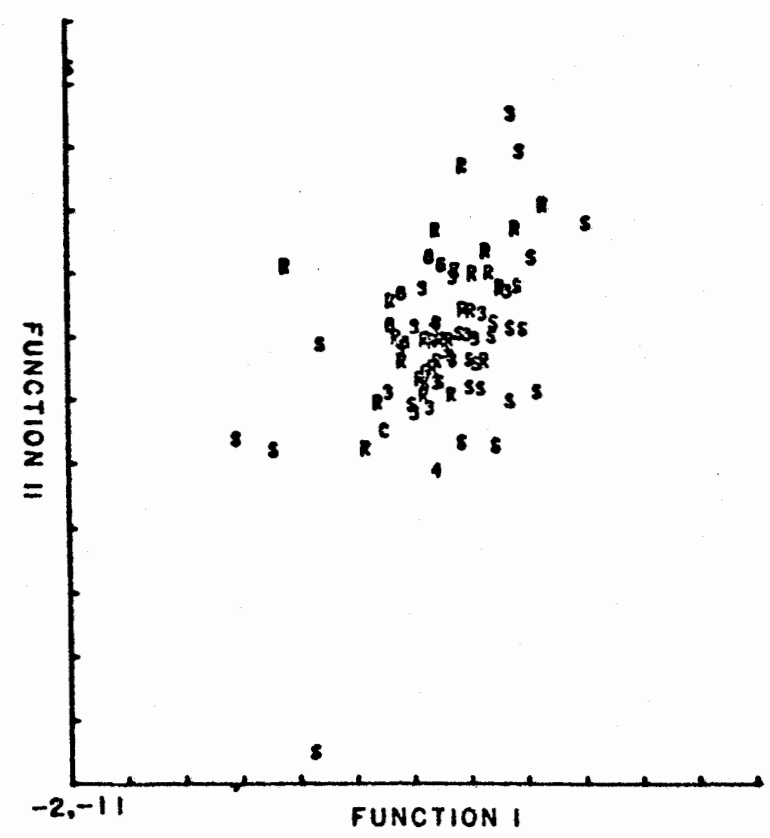

Figure 5. Graph of discriminant scoras for Group 3 C-Carpentervllio R-Chetco R. 3-Rd. 333 4-Rd. 3400 6-Rd. 3406 S-Snaketooth 
from this population. The scores ranged from -1.3597 to 12.5842 for Function I and from -1.4459 to 8.4770 for Function II (Figure 6). The Discriminant Scores for members of the Iron Mountain II population also varied widely but they form three groups as shown by the graph in Figure 7 . Four cases from this population were classified into Group a while thirteen individuals were placed in Group 3.

The Cluster Analysis program used a Euclidean distance measure to generate three clusters representing the thirteen populations. The populations assigned to each cluster are shown in Table IX. During this analysis members of Iron Mountain II were not consistently assigned to any one of the three clusters.

TABLE IX

CLASSIFICATION OF POPULATIONS USING CLUSTER ANALYSIS

\begin{tabular}{llll}
\hline Cluster 1 & Cluster 2 & Cluster 3 \\
\hline Cape Blanco & Daphne Grove & Carpenterville & Road 3400 \\
Meyers Cr. & Iron Mt. I & Chetco River & Road 3406 \\
Smith River & & Snaketooth & Road 333 \\
Champion Pk. & & \\
\hline
\end{tabular}

Three clusters were found to be optimal in this analysis as further divisions into clusters did not lead to significantly more compact clusters as shown in Table $\mathrm{X}$ where the mean of the mean distances to the cluster center for each cluster is computed for each analysis.

In this analysis, in contrast to the Discriminant Analysis, Champion Park was completely included within a single cluster, Cluster 1 . Members 
32

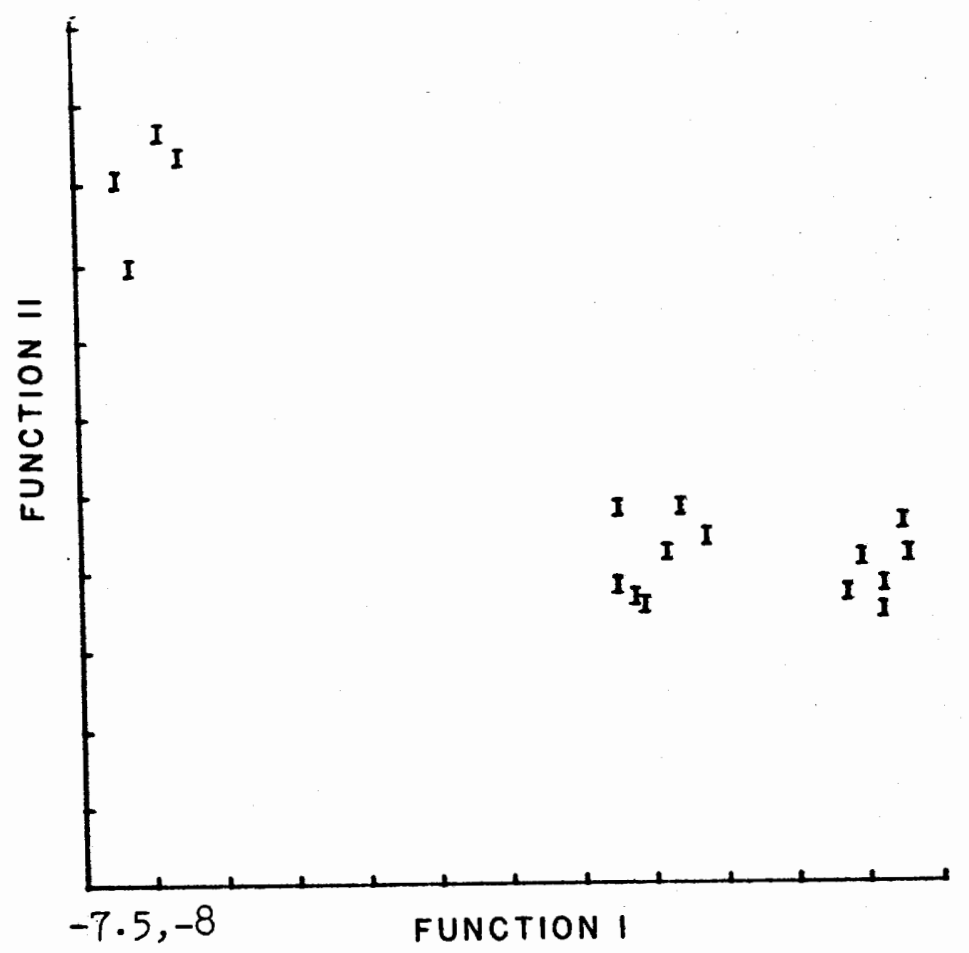

Figure 7. Graph of discriminant scores for Iron Mt. II

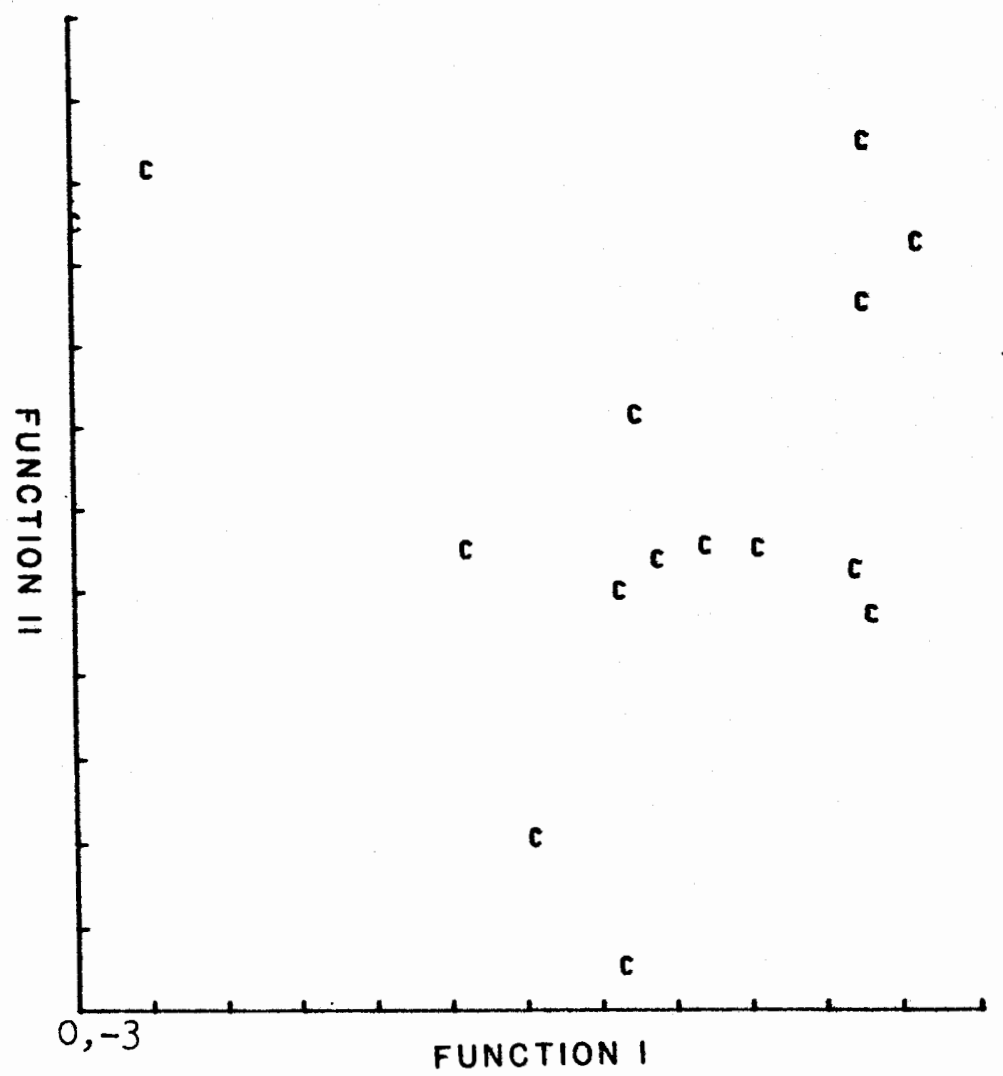

Figure 6. Graph of discriminanant scores for Champion Pk. 
TABLE $X$

A COMPARISON OF THE AVERAGE MEAN DISTANCE TO THE CLUSTER CENTER

\begin{tabular}{ccc}
\hline $\begin{array}{c}\text { \# of } \\
\text { Clusters }\end{array}$ & $\begin{array}{c}\overline{\mathrm{X}} \text { of } \overline{\mathrm{X}} \text { Distance } \\
\text { to Cluster Center }\end{array}$ & $\begin{array}{c}\% \\
\text { Decrease }\end{array}$ \\
\hline 1 & 3.1318 & \\
2 & 2.2480 & 28.22 \\
3 & 1.8323 & 18.49 \\
4 & 1.7834 & 2.61 \\
5 & 1.7543 & 1.63 \\
\hline
\end{tabular}

of this population however, had an average distance to the cluster center which exceeded all other populations except Smith River (Table XI). Individuals from Smith River had definite characters of Cluster I type but were considerably larger in height and bract length and width than other members of this group. Meyers Creek was included in this cluster, however one individual from this population was placed in Cluster 3. That individual had a distance of 5.95379 from the cluster center which exceeds the mean distance for the cluster (Table XI).

Cluster 2 with a mean distance of 1.27196 (Table XI) is the most compact cluster. The mean distance for the cluster is slightly higher than the distances for either population assigned to it. This is due to the placement into this cluster of four individuals from populations where most of the members were assigned to another cluster. Three plants collected from Snaketooth were assigned to Cluster 2 with distances of $2.42215,2.66107$ and 2.18246 , distances well beyond the average for the cluster (Table XI). One individual from Road 333 was also placed in this 
TABLE XI

CLUSTER AND POPULATION MEAN DISTANCES TO CLUSTER CENTER

\begin{tabular}{|c|c|}
\hline Cluster & $\overline{\mathrm{X}}$ Distance \\
\hline 1 & 2.1857 \\
\hline Cape Blanco & 1.6632 \\
\hline Smith River & 2.9919 \\
\hline Meyers Creek & 2.1820 \\
\hline Champion Park & 2.6258 \\
\hline 2 & 1.2719 \\
\hline Daphne Grove & 1.2703 \\
\hline Iron Mountain I & 1.1414 \\
\hline 3 & 2.0394 \\
\hline Chetco River & 1.8707 \\
\hline Road 333 & 1.9760 \\
\hline Road 3400 & 2.0657 \\
\hline Road 3406 & 1.6632 \\
\hline Carpentervilie & 2.4758 \\
\hline Snaketooth & 2.5061 \\
\hline Iron Mountain II & \\
\hline cases classified to Cluster I & 1.1305 \\
\hline cases classified to Cluster 2 & 1.9450 \\
\hline
\end{tabular}


cluster. It had a distance of 2.8914 from the cluster center. The bulk of these populations, 25 cases from Snaketooth and 21 cases from Road 333 were assigned to Cluster 3 .

The mean distance to the cluster center for Cluster 3 was about equal to the distance for Cluster I (Table XI). Snaketooth was the most variable population in this cluster as demonstrated by its average distance to the cluster center and also by the assignment of three plants collected in this population to Cluster 2. Road 333 even though one individual was assigned to Cluster 2 , had an average distance to the center of Cluster 3 which was less than the mean for all the populations.

As found in the discriminant analysis, individuals from Iron Mountain II were classified into more than one cluster. Individuals placed in Cluster 2 had distances to that cluster center that compare closely with other populations in the cluster (Table XI). The individuals that were placed in Cluster 3 also lie well within the cluster when compared to the other populations.

\section{Flavonoid Analysis}

Flavonoid analysis of floral extracts from ten populations lead to three groups with similar flavonoid profiles. Besides the similarity found within the three groups, it was found that three pigments were present in all ten populations'surveyed and two more were found in all but one of the ter populations. The distribution of the fifty one pigments resolved in the study is summarized in Table XII. Of special significance are the pigments which are present in all populations of a group but are absent from all or most other populations. Those flavonoids are consid- 


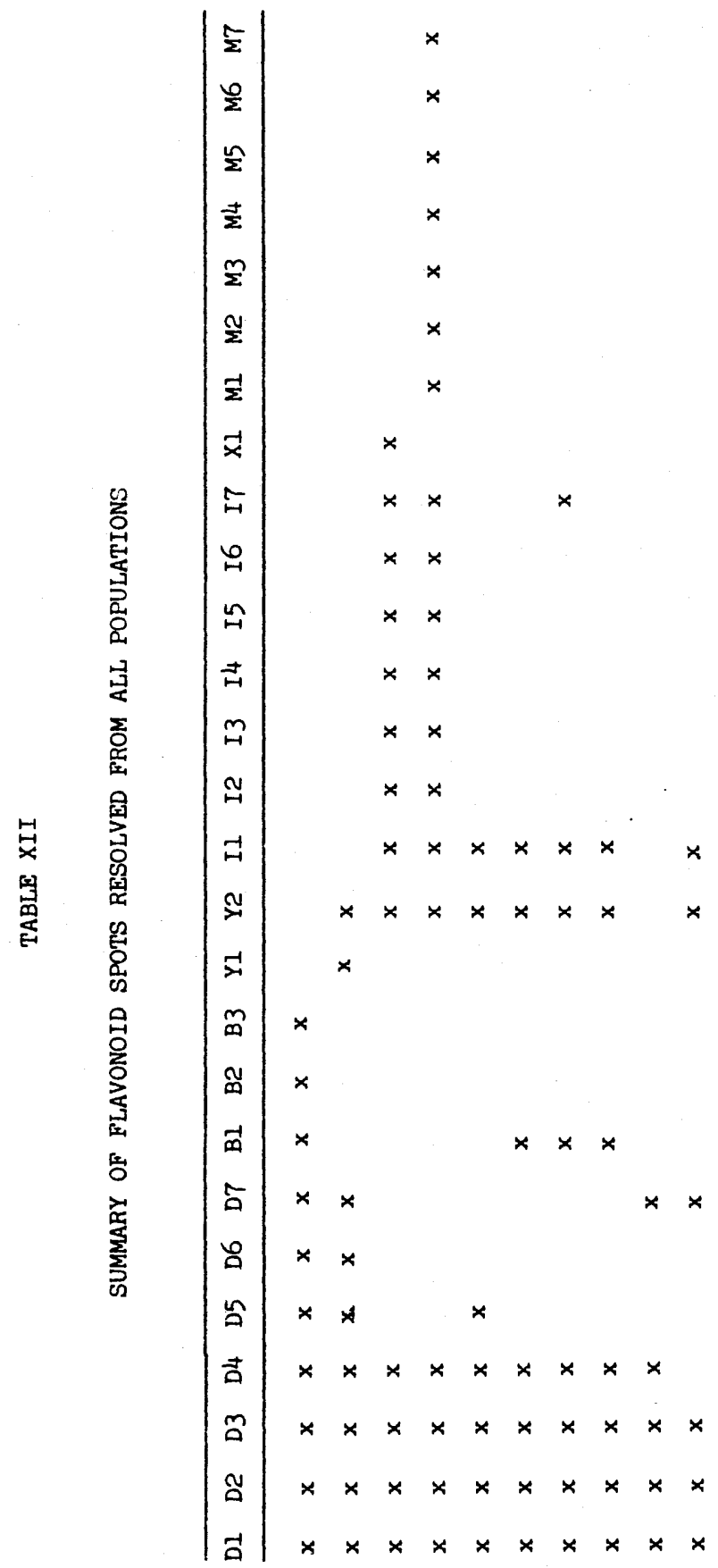

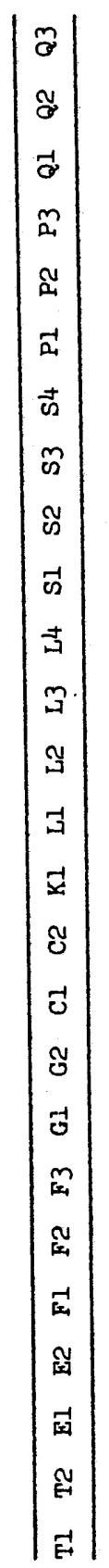

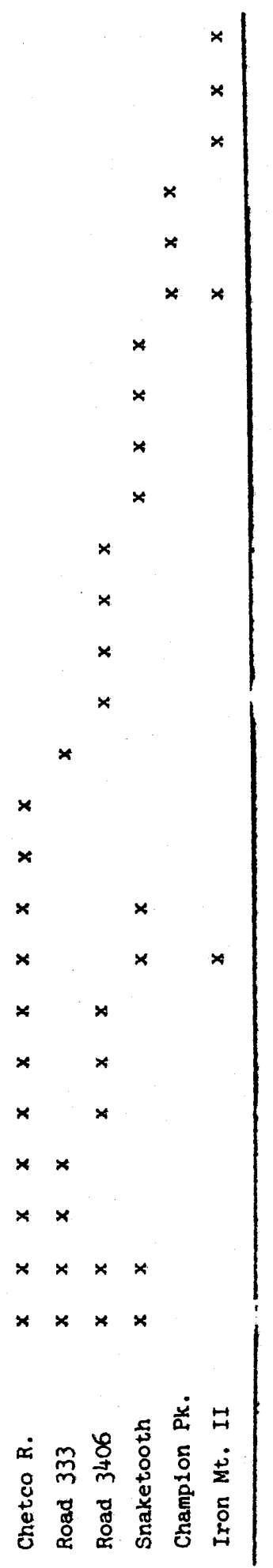

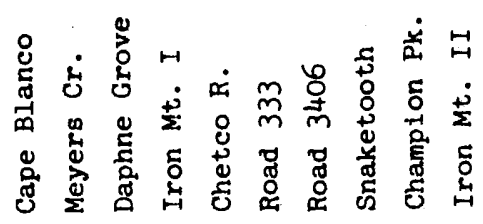

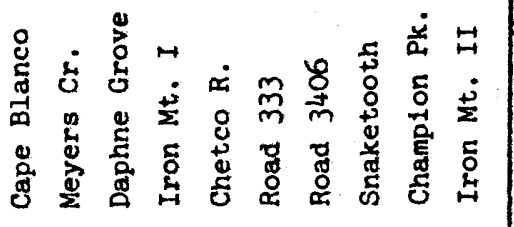


ered characteristic for that group.

Cape Blanco and Meyers Creek formed a group sharing seven of the twelve total pigments resolved from the two populations. Pigment spots $D 5, D 6$ and D7 can be considered characteristic for this group. $R_{f}$ values for the pigments resolved from this group are given in Table XIII and a map of the flavonoid spots is found in Figure 8. Cape Blanco had three

\section{TABLE XIII}

FLAVONOID $R_{f}$ VALUES FOR POPULATIONS OF GROUP 1

\begin{tabular}{lcc}
\hline Spots & $R_{f 1}$ & $R_{f 2}$ \\
\hline D1 & .231 & .073 \\
D2 & .218 & .221 \\
D3 & .964 & .951 \\
D4 & .967 & .734 \\
D5 & .970 & 0 \\
D6 & .948 & .426 \\
D7 & .934 & .832 \\
\hline B1 & .958 & .192 \\
B2 & .936 & .624 \\
B3 & .981 & .772 \\
Y1 & .066 & .031 \\
\hline
\end{tabular}


unique pigments while Meyers Creek contained two pigments not found in the Cape Blanco population.

Twenty spots were resolved in the second group which contains Daphne Grove and Iron Mountain I populations. Of the twenty flavonoids twelve spots were shared by the two populations. The spots which characterize this group are: I2, I3, I4, I5, I6 and I7. The $R_{f}$ values of the twenty flavonoid spots are given in Table XIV and a flavonoid map for the group is found in Figure 9. Seven pigments were resolved from the Iron Mountain I population that were not present in Daphne Grove while one pigment was unique to Daphne Grove.

The third group which is composed of the Chetco River, Road 333, Road 3406 and Snaketooth populations had a total of twentynine pigments of which eight were shared by all four populations. Another pigment was shared by Snaketooth, Road 333 and Road 3406 but was absent from Chetco River. $R_{f}$ values are given in Table $X V$ and the pigment spots are mapped in Figure 10. Chetco River shared two spots with Road 333, two spots with Snaketooth and three spots with Road 3406. Snaketooth was not found to. have spots in common with Road 3406 or Road 333 except in conjunction with other populations as already outlined. Similarily, Road 3406 and Road 333 did not share any unique pigments. Each population was also found to have between one and five flavonoids not found in the other three populations. Pigment spots $\mathrm{Tl}$ and $\mathrm{T} 2$ characterize this group.

Eight pigments were resolved from Champion Park extracts of which two are unique to the population. One of three pigment spots which are characteristic for Group 1 were resolved in this population. The $R_{f}$ values for the eight pigments are given in Table XVI and the spots are mapped 
TABLE XIV

FLAVONOID $R_{f}$ VALUES FOR POPULATIONS OF GROUP 2

\begin{tabular}{|c|c|c|}
\hline Spots & $R_{f 1}$ & $\mathrm{R}_{\mathrm{f2}}$ \\
\hline $\mathrm{DI}$ & .231 & .073 \\
\hline D2 & .218 & .221 \\
\hline D3 & .964 & .951 \\
\hline D4 & .967 & .734 \\
\hline ч2 & .420 & 0 \\
\hline II. & .393 & .353 \\
\hline I2 & .976 & .622 \\
\hline I3 & .936 & .624 \\
\hline I4 & .916 & .706 \\
\hline 15 & .850 & .372 \\
\hline I6 & .944 & .870 \\
\hline I7 & .868 & .270 \\
\hline \multicolumn{3}{|c|}{ (unique to Daphne Grove) } \\
\hline$X 1$ & .529 & .198 \\
\hline \multicolumn{3}{|c|}{ (unique to Iron Mountain I) } \\
\hline MI & .979 & .341 \\
\hline M2 & .748 & .429 \\
\hline M3 & .566 & .824 \\
\hline M4 & .524 & .612 \\
\hline M5 & .573 & .576 \\
\hline M6 & .615 & .624 \\
\hline M7 & .670 & .565 \\
\hline
\end{tabular}


TABLE XV

FLAVONOID $R_{f}$ VALUES FOR POPULATIONS OF GROUP 3

\begin{tabular}{lcc}
\hline Spots & $R_{f 1}$ & $R_{f 2}$ \\
\hline D1 & .231 & .073 \\
D2 & .218 & .221 \\
D3 & .964 & .951 \\
D4 & .967 & .734 \\
Y2 & .420 & 0 \\
I1 & .393 & .353 \\
T1 & .434 & .240 \\
T2 & .896 & .606 \\
\hline
\end{tabular}

(common to $\mathrm{SN}, 34 \& 33$ )

B1

.558

.192

(common to $\mathrm{CH} \& 33$ )

El

.966

.359

E2

.959

.224

\section{(common to $\mathrm{CH} \& 34$ )}

$\begin{array}{llr}\text { F1 } & .869 & .179 \\ \text { F2 } & .961 & .543 \\ \text { F3 } & .787 & .668\end{array}$

(common to $\mathrm{CH} \& \mathrm{SN}$ )

GI

.926

.460

G2.

.805

.456 
Table XV continued

\begin{tabular}{|c|c|c|}
\hline Spots & $\mathrm{R}_{\mathrm{II}}$ & $R_{f 2}$ \\
\hline & (unique to $\mathrm{CH}$ ) & \\
\hline D5 & .970 & 0 \\
\hline $\mathrm{Cl}$ & .974 & .185 \\
\hline $\mathrm{C} 2$ & .974 & .247 \\
\hline & (unique to 33 ) & \\
\hline$K I$ & .338 & 0 \\
\hline & (unique to 34 ) & \\
\hline I7 & .868 & .270 \\
\hline $\mathrm{LI}$ & .480 & .590 \\
\hline L2 & .855 & .400 \\
\hline L3 & .774 & .193 \\
\hline YI & .079 & 0 \\
\hline & (unique to $\mathrm{SN}$ ) & \\
\hline $\mathrm{SI}$ & .195 & .368 \\
\hline s2 & .490 & .176 \\
\hline s3 & .872 & .772 \\
\hline 54 & .805 & .456 \\
\hline
\end{tabular}

abbreviations: $\quad \mathrm{SN}=$ Snaketooth, $34=$ Road 3406, 33=Road 333, $\mathrm{CH}=$ Chetco River 


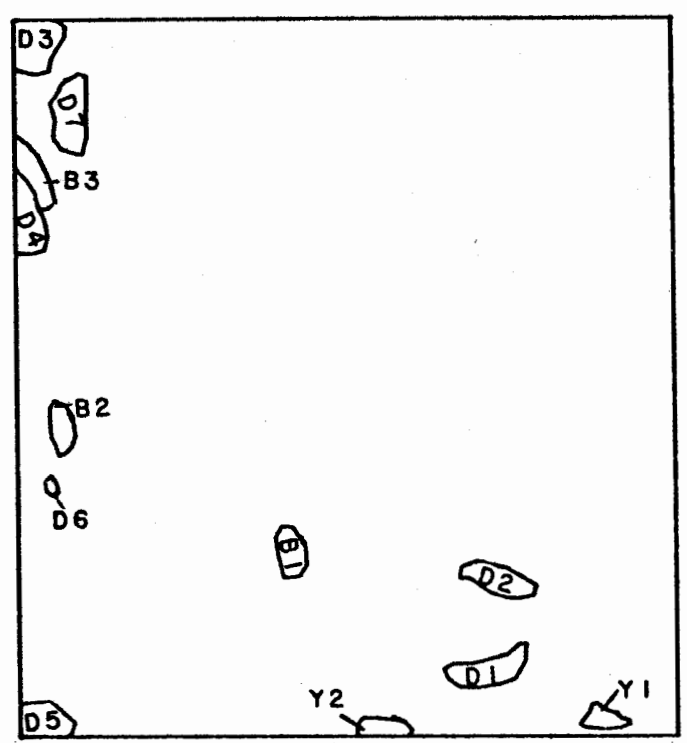

Figure 8. Map of flavonoid spots, Group 1

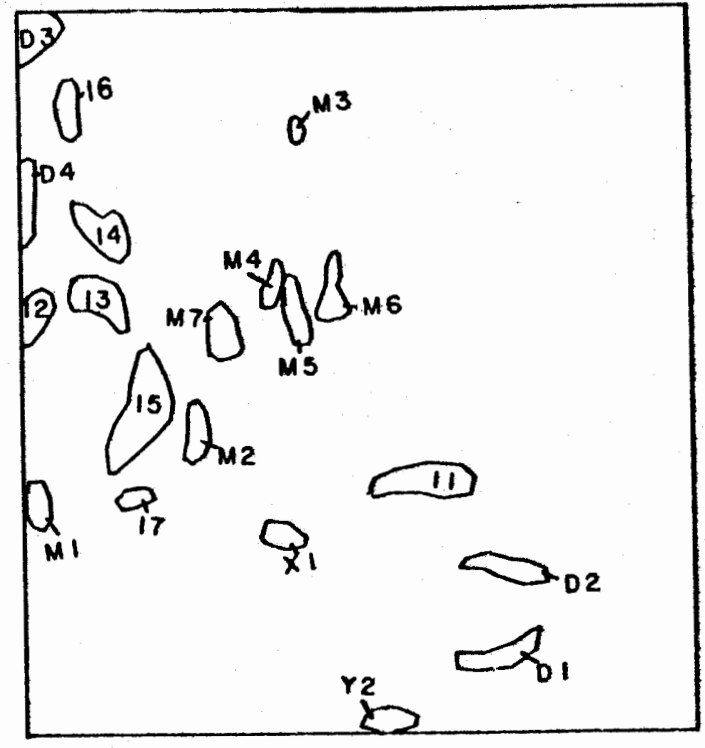

Figure 9. Map of tlavenoid epote, Group 2

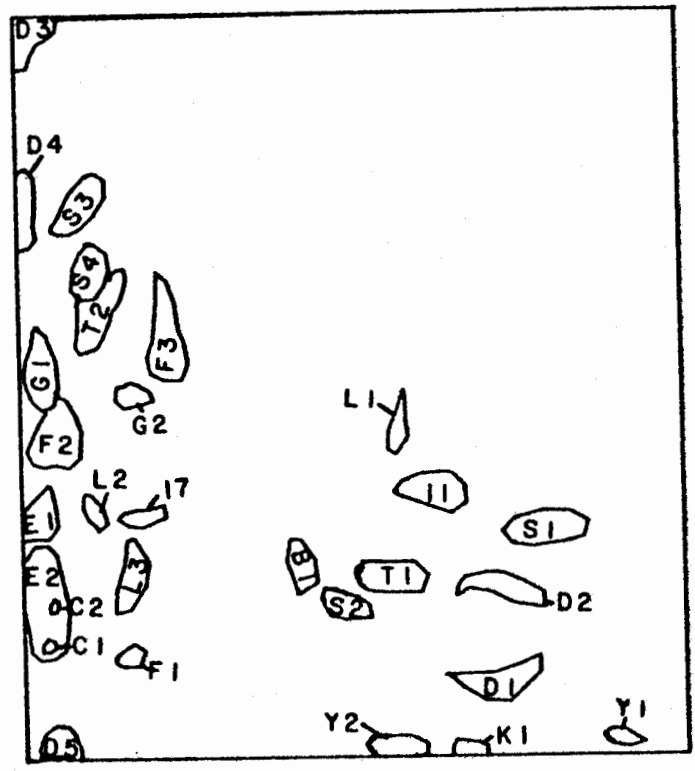

Figure 10. Map of Plavonold spots, Group 3 
in Figure 11. Champion Park shares one pigment spot with Iron Mountain II which is not found in any other population.

Iron Mountain II contained eleven pigments of which three were unique. $R_{f}$ values for the eleven pigments are given in Table XVII and the spots are mapped in Figure 12. A spot characterizing the third group was found in this population but other characterizing pigments were not resolved from the extract.

TABLE XVI

FLAVONOID $R_{f}$ VALUES FOR CHAMPION PARK

\begin{tabular}{ccc}
\hline Spots & $R_{f I}$ & $R_{f 2}$ \\
\hline D1 & .231 & .073 \\
D2 & .218 & .221 \\
D3 & .964 & .951 \\
D4 & .967 & .734 \\
D7 & .934 & .832 \\
P1 & .757 & .977 \\
& $(u n i q u e)$ & .684 \\
P2 & .616 & .872 \\
P3 & .709 & .972 \\
\hline
\end{tabular}


TABLE XVII

FLAVONOID $R_{f}$ VALUES FOR IRON MOUNTAIN II

\begin{tabular}{ccc}
\hline Spots & $R_{f l}$ & $R_{f 2}$ \\
\hline D1 & .231 & .073 \\
D2 & .218 & .221 \\
D3 & .964 & .951 \\
Y2 & .420 & 0 \\
I1 & .393 & .353 \\
D7 & .934 & .832 \\
G1 & .926 & .460 \\
P1 & .757 & .977 \\
Q3 & .923 & .618 \\
Q2 & $(u n i q u e)$ & .212 \\
& .917 & 415
\end{tabular}




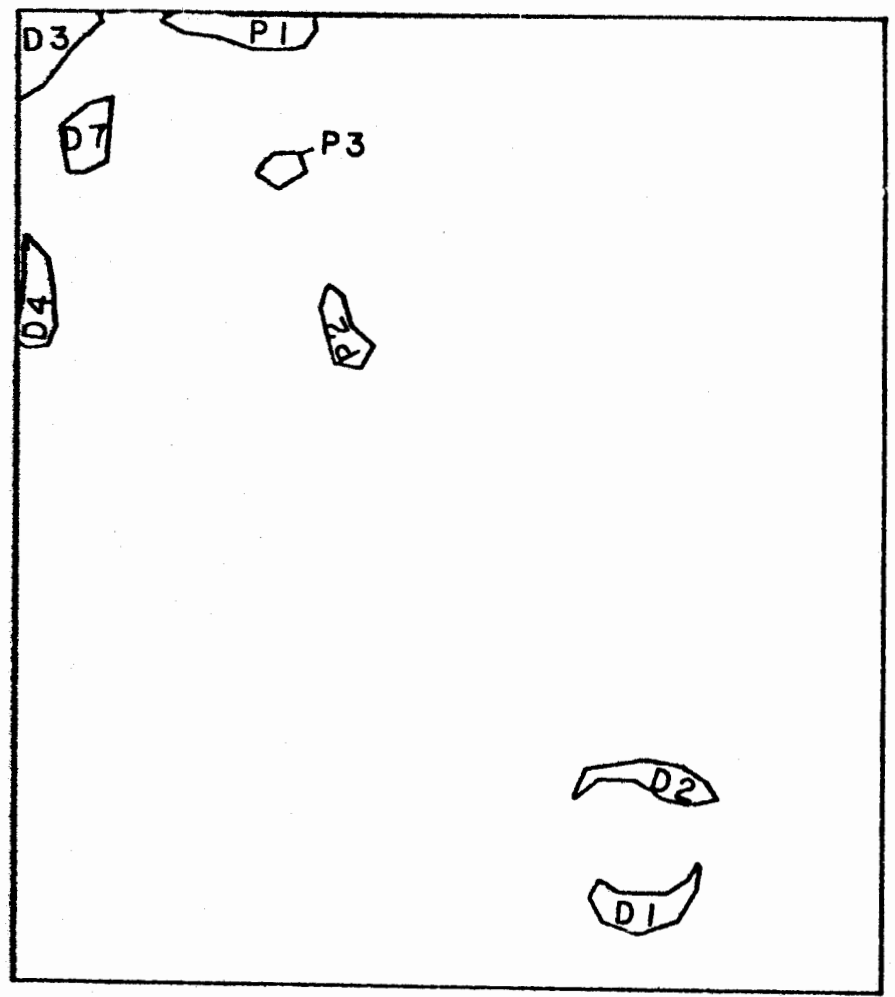

Figure 11. Map of flavonoid spots, Champion Pk.

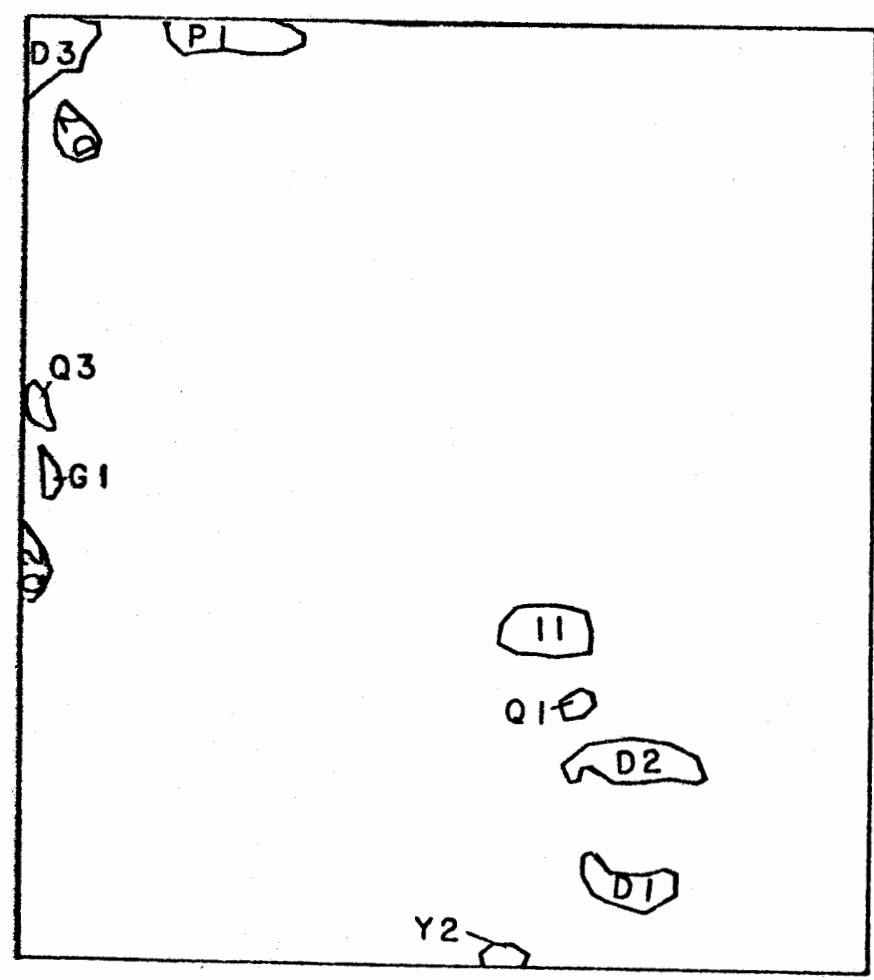

Figure 12. Map of flavonoid spots, Iron Mt. II 


\section{CHAPTER VII}

\section{DISCUSSION}

\section{Taxonomy}

Taxonomists agree that these species of Iris are closely related but have not agreed upon their status. Lenz recognised two species and placed Iris thompsonii within the species Iris innominata, considering it a hybrid between Iris innominata and Iris douglasiana in some populations and a color form not of hybrid origin in other populations. Clarkson concluded from his work that three taxa existed within the group and that I. thompsonii was a probable hybrid between the other two species.

The close evolutionary relationship recognized by earlier workers was supported in this study by the presence of three flavonoid pigments in all ten populations of the three species that were surveyed and the presence of two more pigments in nine of the ten populations. Both the morphological and flavonoid data support the recognition of three species: Iris douglasiana, Iris innominata and Iris thompsonii. During the Discriminant Analysis, the classification of the thirteen populations into three groups was found to be highly significant and during the Cluster Analysis three clusters were found to be optimum. The flavonoid data futher supports this taxonomy by the presence of characteristic pigments in populations belonging to each of the three species. The floral color, which is often burgundy, blue or lavendar, is variable in $I$. thompsonii and could be considered intermediate to the yellow floral color of I. innominata and purple color of $I$. douglasiana. More than $60 \%$ of the flavonoids resolved are not present in the other two species, indicating that the apparent intermediate color is not a blending of yellow and purple pigments but a syn- 
thesis of unique flavonoids.

I. douglasiana is represented by the Cape Blanco, Meyers Creek and Smith River populations. Daphne Grove and Iron Mountain I are populations of I. innominata: I. thompsonii populations include Carpenterville, Chetco River, Road 333, Road 3400, Road 3406 and Snaketooth. Where these and other populations of the species are sympatric hybridization is possible and no doubt occurrs. The level of gene flow occurring is not sufficient to have led to a "hybrid swarm" condition, indicating that isolating mechanisms such as blooming times and habitat preferences which were discussed in Chapter IV must be operating to reduce hybridiation. Iris douglasiana populations were found to bloom late with peak blooming time in June and considerable blooming into mid-July except for at Meyers Creek where blooming began in March and continued through June. I. innominata was found to bloom earlier with the peak bloom date in May, thus reducing possible hybridization. I. thompsonii was found to bloom earlier than the other two species although blooming was more variable and overlap with $I$. innominata is possible as Road 333 is at peak bloom also in May. Possible overlap with blooming dates of $I$. douglasiana might lead to hybridization near Carpenterville as both species are found in this area, however no hybrids were located.

Although ecological parameters were not extensively explored in the study, habitat preference was determined by evidence or lack of evidence for the presence of serpentine soils. Iris innominata is associated with sparsely vegetated, serpentine soils. Iris thompsonii is associated with more diverse soils. It was found at Carpenterville where serpentine soil is present, at Snaketooth and Road 3400 where there was no evidence for 
serpentine and at several locations where the soil was intermediate either in the nitrogen to base ratio or in vegetation type. Overall $I$. thompsonii occupied intermediate soils in most cases. Iris douglasiana on the other hand is associated with nonserpentine soils at most sites. Most populations of the species are found within a few miles of the ocean where serpentine is not found. One site which was studied at Meyers Creek had serpentine soil but the amount of moisture present at this site would decrease the toxic effects of the soils. The unique character of the Siskiyou Mountains with their unusual serpentine areas, led to a distribution for the species as shown in Figure 12. Iris innominata is found only in the extreme northern part of the study area where sparsely vegetated, serpentine soils are found, Iris douglasiana is restricted to a long narrow belt along the western edge of the study area and within a couple of miles of the ocean where soils tend to be nonserpentine and Iris thompsonii has a more general distribution throughout the study area. It also occupies a more diverse habitat than the other species. It is found in light shade with grasses, a habitat type more often associated with Iris douglasiana and also open gravelly, intermediately serpentine areas. It was never found however in habitats as depauperate of vegetation as is typical of Iris innominata. Thus habitat preference and the resulting distribution of the three species throughout the study area could well act as isolating mechanisms.

Origin of Iris Thompsonii

Hybridization among members of this series has been documented by several workers. Both Lenz and Clarkson concluded that Iris thompsonii 


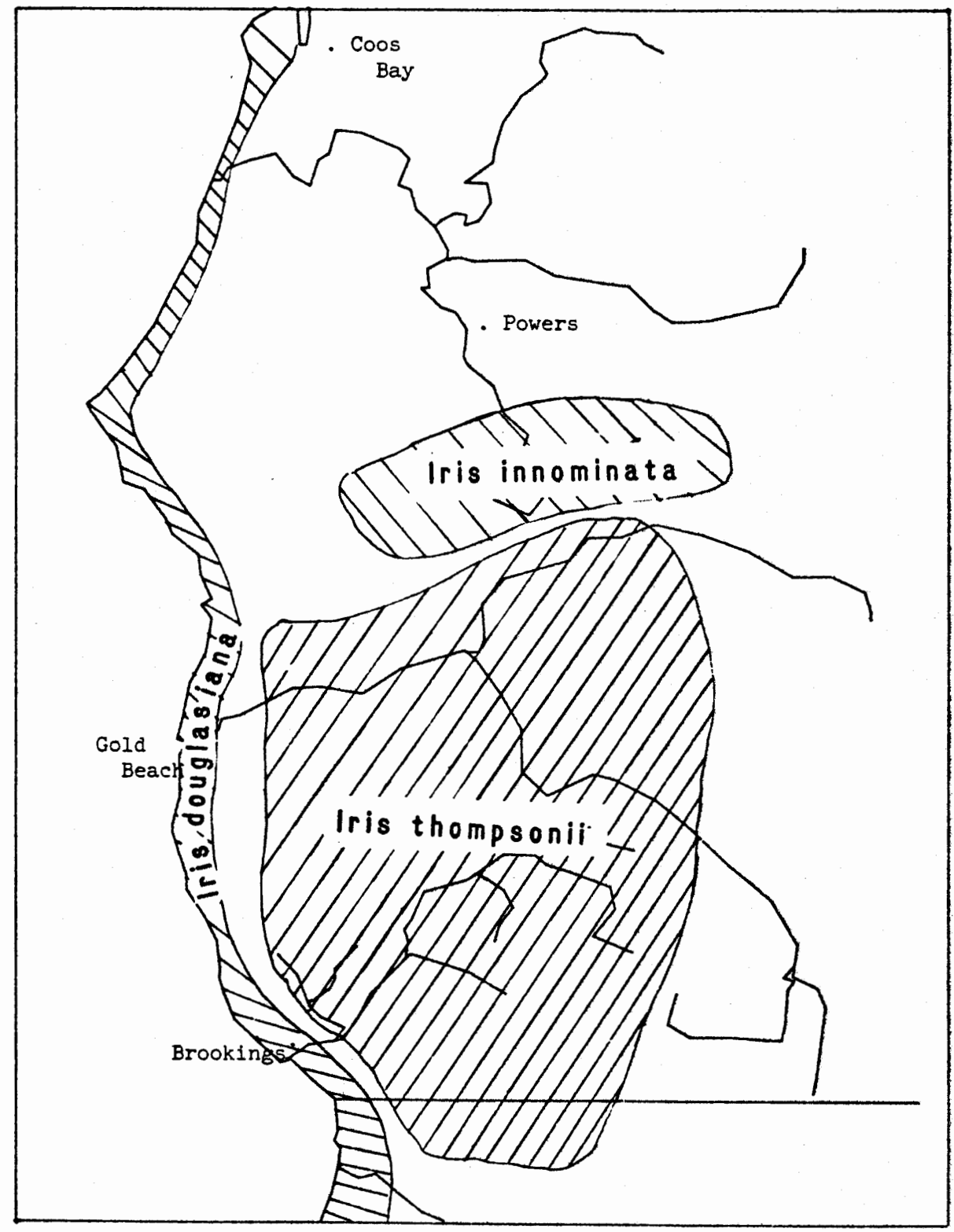

Figure 13. Map of study area showing species distribusion 
was of hybrid origin from the proposed parents, Iris douglasiana and Iris innominata. Their conclusions were based upon the intermediate morphology of the species and its flower color which ranged from cream to purple. In the present study morphological characters were analysed and the expected outcome was an intermediate condition if $I$. thompsonii is of hybrid origin. The analysis of flavonoids for a diploid hybrid should result in a pigment profile intermediate between the two parents where pigments common to both parents would be present but not all pigments would be represented. It is also possible that hybridization could result in a reduced pigment profile, if the hybrid was unable to produce the complementary enzymes necessary to complete biosynthetic pathways found in the parents. Such a genome would be expected if the parents produced flavonoids which were considerably different and involved quite divergent pathways for synthesis.

of ten quantitative, morphological characters used in the discriminant Analysis, all but three were intermediate for $I$ : thompsonii. The mean values for the number of cauline leaves and sepal width were less than values for the proposed parents. Floral tube length was found to be $147 \%$ as long as that for $I$. douglasiana and $117 \%$ as long as the mean tube length for $I$ : innominata. Floral tube length may play an important role in pollinator selection within this group and speciation of $I$. thompsonit. Bumblebees were observed pollinating the species in the field.

In flavonoid characters, I. thompsonii had one pigment,.Il, which is characteristic for I. innominata and one pigment, B3, which is present in extracts of Cape Blanco, a population of I. thompsonii. The Chetco River population contained D5, which characterizes I. douglasiana. I. thompsonii also produces a large number of other pigments, many of which are unique to 
the species. While the flavonoid data support a relationship among the species, there is no clear support for the hypothesis of a hybrid origin for 1 . thompsonii. The lack of clear support could be due to the time of hybridization. If the species is of hybrid origin, sufficient time has elapsed for the development of a varied and unique flavonoid profile. The presence of a large number of new flavonoids does not exclude the possibility of a hybrid origin, as such variation could be explained by the heterogeneity brought about by hybridization and the resulting development over time of new biosynthetic pathways. The lack of clinal differences in morphological and flavonoid data also supports a relatively old origin for the species if it is a hybrid. The presence of nine flavonoids in the Chetco River population of $I$. thompsonit from the southern part of its range which are also present in the northern populations of Road 333 and Road 3406 suggest that many of the unique pigments developed before the species became distributed to the south. One would assume a southern movement for the species if it is a hybrid of the northern species, I. innominata with $I$ : douglasiana:

Intraspecific Variation

Besides the variation found among the three species considerable variation was also found within some some species. I. innominata is the least variable species. Compact clusters resulted during the K-Means Analysis and similar Discriminant Scores were found for the populations with the Discriminant Analysis. Its flavonoid profile also shows considerable homogeneity. Twelve of the twenty flavonoids resolved were shared by both populations.

I. douglasiana is more variable than $I$. innominata as indicated by its greater average distance to the cluster center. The inclusion of 
Champion Park within this cluster inflates its distance somewhat. The graph of Discriminant Scores also clearly shows the greater variability of this species. The flavonoid chemistry of the species is less variable than the morphological data. Of twelve flavonoids resolved in the species, seven were found in all populations surveyed.

Both the morphological and flavonoid data indicates a more variable nature for $I$. thompsonii. The average distance to the cluster center for this group is slightly less than for $I$. douglasiana, however the Discriminant Scores showed greater variability and the standard deviations for $z$ morphological characters used were greatest for this species. The radiation of flavonoids within the species is striking. Of twentynine pigments resolved only eight were shared by all of the populations. The greater variation found in I. thompsonii may be due to its relatively larger range and more variable habitat which could lead to isolation of populations and a greater resulting variation between these populations.

\section{Current Hybridization}

Two populations, Champion Park and Iron Mountain II, do not clearly belong to any one of the three species studied and may represent current hybridization among the species. Champion Park is most closely aligned to $I$ : douglasiana as indicated by the inclusion of this population into the species during the Cluster Analysis. It is found however, to be somewhat intermediate as shown by the assignment of two of its merabers to $I$. innominata and two of its members to $I$. thompsonii during the Discriminant Analysis. The decreased number of flavonoids suggests also a hybrid origin as biosyntheic pathways may have been interrupted. The evidence may indicate a hybridization event in response to the movement of $I$. douglas- 
iana inland during the logging of the study site. I. thompsonit populations are located within one mile of the site.

Numerical analysis of Iron Mountain II indicates that it may be two populations, one of $I$. innominata and one of $I$. thompsonii. During the K-Means Analysis the individuals were well within the cluster they were assigned to and during the Discriminant Analysis the population, unlike the Champion Park population which showed no pattern when graphing Discriminant scores, formed three groups. The three groups represent the two populations and a third intermediate group between $O$ and $I$ on the $X$ axis and between -3 and -5 on the $Y$ axis, which could be hybrids between the two species. The flavonoid data has a reduced number of pigments which would be expected if the population is a mixed population consisting of the two species and hybrids, as the pigments of both species would be diluted into amounts which might not be detectable. 


\section{CONCLUSIONS}

A study of populations of Iris found on the western slopes of the Siskiyou Mountains in Curry County, Oregon and Del Norte County, California, lead to the following conclusions:

1. The populations can be assigned to three species: Iris douglasiana, Iris innominata and Iris thompsonii. Blooming times and habitat preferences may contribute to isolation of the species.

2. Iris thompsonii is intermediate in most morphological characters and shares some flavonoid pigments with the other species, but is sufficiently distinct to suggest that if it originated as a hybrid as suggested by previous workers, the hybridization event was not recent.

3. Differences exist in the amount of intraspecific variation between the species. Iris innominata populations are quite homogeneous while populations of Iris thompsonii show striking differences. Iris douglasiana is intermediate in the amount of intraspecific variation. The amount of variation found may be associated with the restriction or nonrestriction of the species to a small range and homeogeneous habitat.

4. Probable current hybridiation can be seen in the Champion Park and Iron Mountain II populations. Champion Park may well be a hybrid population with Iris thompsonii and Iris douglasiana as the proposed parents. Iron Mountain II may be three groups of plants, one a population of Iris innominata, one a population of Iris thompsonii and one a population of hybrids of the two species. 


\section{LITERATURE CITED}

Baldwin, E. M. 1981. Geology of Oregon. Kendall/Hunt Publishing Co., Toronto.

Clark, W. D., G. K. Brown and R. L. Mays 1980. Flower flavonoids of Opuntia series Opuntia. Phytochemistry, 19:1856-1857.

and B. D. Parfitt 1980. Flower flavonoids of Opuntia subgenus

T Cylindropuntia. Phytochemistry, 19:2042-2043.

Clarkson, Q. D. 1958. Iris, section Apogon, subsection Oregonae subsect. nov. Madroño, 14(7):246-247.

1959. Field studies of natural hybridization in the Oregon species of Iris L. subsection Californicae Diels. Madroño, 15(4): 115-122.

1962. Ecological factors in the hybridization of Iris tenax douglasiana (Herbert) Clarkson and Iris tenax innominata (Henders.) Clarkson. Northwest Science, 36(3):59-64.

Clevenger S. 1964. Flower Pigments. Scientific American, June, p85.

Diels, L. 1930. Iridaceae in Engler and PrantI. Die Naturlichen Pflanzenfamilien. Berlin.

Duncan, T. 1980. Cladistics for the practising taxonomist an eclectic view. Systematic Botany, 5(2):136-148.

Dykes, W. R. 1913. The Genus Iris. Cambridge University Press, Cambridge.

Elkington, T. T. and A. Badr 1978. Numerical taxonomy of species in Allium subgenus Molium. New Phytologist, 81:401-417.

Foster, R. C. 1937. A cyto-Taxonomic survey of the North American species of Iris. Contr. Gray Herb., No. CXIX.

Hannan, G. L. 1981. Flower color polymorphism and pollination biology of Platystemon californicus Benth. (Papaveraceae). Amer. J. Bot., 68 (2):233-243.

Harborne, J. B., T. Mabry and H. Mabry (Editors) 1975. The Flavonoids. Academic Press Inc., New York.

Hartigan, J. A. 1975. Clustering Algorithms. Wiley, New York.

Jordene, N. and J. M. Edmonds 1974. The use of numerical methods to describe population differentiation. New Phytologist, 73:1259-1277. 
Kruckeberg, A. R. 1954. III. Plant species in relation to serpentine soils. Ecology, 35(2):267-274.

Lawerence, G. 1953. A reclassification of the genus Iris. Gentes Herb., $8: 346-371$.

Lenz, L. 1958. A revision of the Pacific Coast irises. Aliso, 4(1):1-72.

1959a. Hybridization and speciation in the Pacific Coast irises. Aliso, $4(2): 237-309$.

1959b. Iris tenuis S. Wats., A new transfer to the subsection Evansia. Aliso, 4(2):311-319.

Levy, M. and D. Levin 1975. The novel flavonoid chemistry and phylogenetic origin of Phlox floridana. Evolution, 29:487-499.

Markham, K. R. 1982. Techniques of Flavonoid Identification. Academic Press, New York.

Nie, Hull, Jenkins, Sleintrenner, and Brent 1975. Statistical Package for the Social Sciences. McGraw Hill, New York.

Parks, C. R. 1965. Floral pigmentation studies in the genus Gossypizm. I. Species specific pigmentation patterns. Amer. J. Bot., 52(3): 309-316.

1967. Floral pigmentation studies in the genus Gossypium. III. Qualitative analysis of total flavonal content for taxonomic studies. Amer. J. Bot.; 54(3):306-315.

Swain, T. 1973. Flavonoids as evolutionary markers in primative tracheophytes. Nobel 25 Chemistry in Botanical Classification.

Umber, R. E. 1980. The flavonoid chemistry of Glandularia bipinnatifida (Verbenaceae) and allied species. Amer. J. Eot., 67(6):935-941.

Wagner, W. 1980. Origin and philosophy of the groundplan-divergence method of cladistics. Syst. Bot., 5(2):173-193.

Walker, R. B. 1954. II. Factors affecting plant growth on serpentine soils. Ecology, 35(2):259-266.

White, C. D. 1971. Vegetation--Soil Chemistry Correlations in Serpentine Ecosystems. Thesis, University of Oregon. 